\title{
Effects of image pansharpening on soil total nitrogen prediction models in South India
}

\author{
Yiming Xu ${ }^{\mathrm{a}, \mathrm{b}, \mathrm{c}, *}$, Scot E. Smith ${ }^{\mathrm{b}, \mathrm{c}}$, Sabine Grunwald ${ }^{\mathrm{b}, \mathrm{d}}$, Amr Abd-Elrahman $^{\mathrm{c}, \mathrm{e}}$, Suhas P. Wani ${ }^{\mathrm{f}}$ \\ ${ }^{a}$ Department of Environmental Science and Engineering, Beijing Technology and Business University, Beijing 100048, China \\ b School of Natural Resource and Environment, University of Florida, 103 Black Hall, PO Box 116455, Gainesville, FL 32611, USA \\ ${ }^{\mathrm{c}}$ School of Forest Resources and Conservation - Geomatics Program, University of Florida, 301 Reed Lab, PO Box 110565, Gainesville, FL 32611-0565, USA \\ d Pedometrics, Landscape Analysis and GIS Laboratory, Soil and Water Sciences Department, University of Florida, 2181 McCarty Hall, PO Box 110290, Gainesville, FL \\ 32611, USA \\ e Gulf Coast REC/School of Forest Resources and Conservation - Geomatics Program, University of Florida, 1200 N. Park Road, Plant City, FL 33563, USA \\ ${ }^{\mathrm{f}}$ International Crops Research Institute for the Semi-Arid Tropics (ICRISAT), Patancheru 502324, Hyderabad, India
}

\section{A R T I C L E I N F O}

\section{Editor: A.B. McBratney}

Keywords:

Image pansharpening

Digital soil models

Soil total nitrogen

Remote sensing

Smallholder farm settings

\begin{abstract}
A B S T R A C T
Image fusion is in its infancy in the application of Digital Soil Mapping, and the incorporation of the image pansharpened spectral indices into the soil prediction models has seldom been analyzed. This research performed image pansharpening of Landsat 8, WorldView-2, and Pleiades-1A in a smallholder village called Masuti in South India using three pansharpening techniques: Brovey, Gram-Schmit (GS), and Intensity-Hue-Saturation (IHS) methods. The research analyzed the relationships between multispectral (MS) and pansharpened (PAN) spectral indices and soil total nitrogen (TN), developed the soil TN prediction models using Random Forest methods, and explored the effects of different PAN spectral indices on soil TN prediction models. The results showed the spectral behavior of PAN spectral indices and MS spectral indices were similar. The results also demonstrated that soil TN models based on MS/PAN spectral indices have slightly higher model performance and more detailed characterization of TN spatial pattern compared with soil TN models based on MS spectral indices. Soil TN models based on the GS PAN and MS spectral indices attained slightly higher prediction accuracy compared with those based on other PAN and MS spectral indices. This research advocates the promotion of image pansharpening techniques in digital soil mapping and soil nutrient management research.
\end{abstract}

\section{Introduction}

Smallholder farmers in Africa and Asia face severe problems such as poverty, hunger, malnutrition, and degradation of natural resources (e.g., water, soil and food insecurity). Smallholder farmers across the globe, and specifically in food-insecure regions are more vulnerable to climate change, water shortages, and market volatility, as they lack enough technical and financial support to increase their grain products and alleviate their vulnerability (Lobell et al., 2008). Up-to-date soil maps and derivative soil management recommendations can help address food security, climate change, water scarcity, and degradation of biodiversity (Sanchez et al., 2009).

To solve global challenges such as food security, soil security and climate change, it is important to characterize the physical, chemical, biological, and hydrologic conditions of the ecosystem, analyze the relationships between anthropogenic activity and the ecosystem, and understand the interactions between policy choice and complex socio- economic and environmental processes (Grunwald et al., 2011; Kelly (Letcher et al., 2013). To develop a sustainable soil and agricultural management scheme in smallholder farm settings, it is imperative to map soil nutrients to guide smallholder farmers' fertilizer application, tillage methods and other farming activities. However, soil prediction models based on spectral indices from some multispectral images are too coarse to characterize spatial patterns of soil properties in small and heterogeneous agricultural land in small farms. Those maps have limited abilities to provide site-specific soil nutrient management suggestions for smallholder farmers.

The image pansharpening technique can incorporate additional panchromatic band information. After incorporating the pansharpened spectral indices into the soil prediction models, it has potential to increase the spatial resolution of soil prediction maps. Remote sensing image fusion techniques such as Gram-Schmit (Laben and Brower, 2000) and Brovey (Vrabel, 2000) have been widely applied to forest management (Lottering and Mutanga, 2016), land use change detection

\footnotetext{
* Corresponding author at: Department of Environmental Science and Engineering, Beijing Technology and Business University, Beijing 100048, China.

E-mail addresses: xuyiming@btbu.edu.cn (Y. Xu), sesmith@ufl.edu (S.E. Smith), sabgru@ufl.edu (S. Grunwald), aamr@ufl.edu (A. Abd-Elrahman), s.wani@cgiar.org (S.P. Wani).
} 


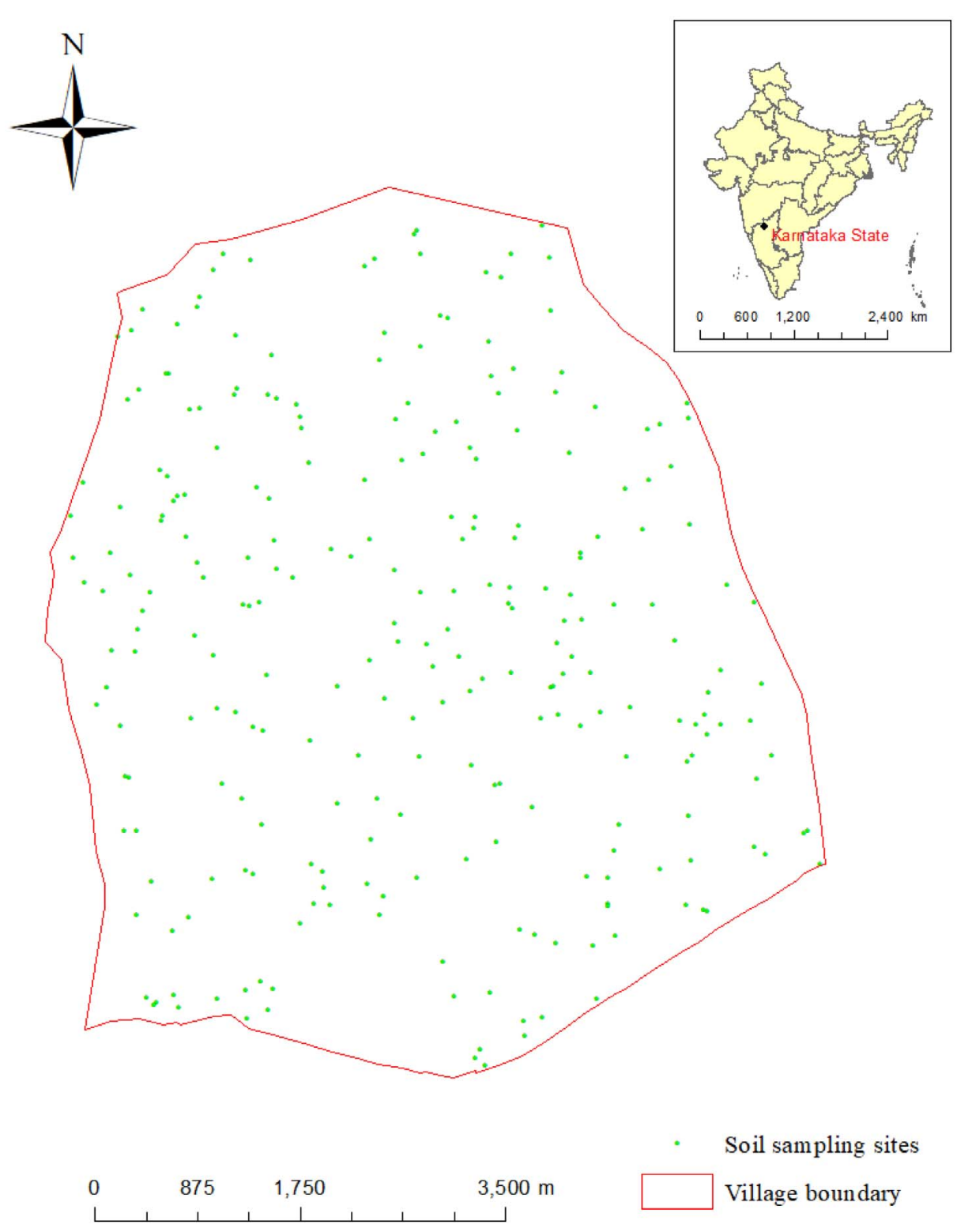

Fig. 1. Soil sampling sites in Masuti village, Karnataka State, India.

Table 1

Remote sensing images utilized in the research.

\begin{tabular}{ll}
\hline Remote sensing images (acquisition date) & Abbreviation \\
\hline Landsat 8 MS image (2013-4-20) & LTa \\
Landsat 8 Brovey PAN image (2013-4-20) & LTaB \\
Landsat 8 GS PAN image (2013-4-20) & LTaG \\
Landsat 8 IHS PAN image (2013-4-20) & LTaI \\
Landsat 8 MS image (2013-5-22) & LTb \\
Landsat 8 Brovey PAN image (2013-5-22) & LTbB \\
Landsat 8 GS PAN image (2013-5-22) & LTbG \\
Landsat 8 IHS PAN image (2013-5-22) & LTbI \\
WorldView-2 MS image (2011-2-28) & WV \\
WorldView-2 Brovey PAN image (2011-2-28) & WVB \\
WorldView-2 GS PAN image (2011-2-28) & WVG \\
WorldView-2 IHS PAN image (2011-2-28) & WVI \\
Pleiades-1A image (2013-3-3) & PL \\
Pleiades-1A Brovey PAN image (2013-3-3) & PLB \\
Pleiades-1A GS PAN image (2013-3-3) & PLG \\
Pleiades-1A IHS PAN image (2013-3-3) & PLI \\
\hline
\end{tabular}

Abbreviations: PAN, pansharpened; MS, multispectral; GS, Gram-Schmidt; IHS, intensity hue saturation.

(Jawak and Luis, 2013), urban planning (Hervieu et al., 2016), and so on. However, the image fusion technique has been seldom applied in digital soil mapping domain before.

Karnataka State has the second largest rainfed agricultural land (5 million ha) in India (Wani, 2012). As an important soil nutrient, total nitrogen (TN) has experienced a continual decrease in soils in southern Indian states such as Karnataka and Kerala in the past decades according to Indian Agricultural Research Institution (Pathak, 2010). A typical smallholder farm called Masuti in Karnatake State was selected as the study area. Some new satellite remote sensing images have strong capacity to provide valuable spectral information for soil prediction model. The new spectral channels of WorldView-2 such as yellow and coastal bands grant the users access to the spectral region which may be overlooked by traditional MS satellite images (Wolf, 2010). The two Thermal Infrared Sensor (TIRS) bands in Landsat 8 image can enable more reliable retrieval of surface temperature and emissivity compared with previous Landsat images (Roy et al., 2014). As a result, Landsat 8, WorldView-2 and Pleiades-1A images were selected to build soil prediction models in this research. This research 1) performed the image pansharpening of Landsat 8, WorldView-2, and Pleiades-1A in Masuti using the Brovey, Gram-Schmit (GS), and Intensity-Hue-Saturation (IHS) methods; 2) extracted multiple spectral indices from multispectral 
Table 2

Environmental variables from remote sensing images.

\begin{tabular}{|c|c|c|}
\hline Environmental variables & Abbreviation & References \\
\hline Spectral reflectance & $\begin{array}{l}\text { Coastal band (Coastal), Blue band (Blue), Green band (Green), Yellow band } \\
\text { (Yellow), Red band (Red), Red edge band (Rededge), Near Infrared band } \\
\text { (NIR), Near Infrared band } 1 \text { (NIR1), Near Infrared band } 2 \text { (NIR2), Short } \\
\text { Wavelength band } 1 \text { (SWIR1), Short Wavelength band } 2 \text { (SWIR2) }\end{array}$ & \\
\hline Band ratio & $\begin{array}{l}\text { Green/Blue ratio (GB), Red/Blue ratio (RB), Red/Green ratio (RG), Red } \\
\text { edge/Blue ratio (REB), Red edge/Green ratio (REG), Red edge/Red ratio } \\
\text { (RER), NIR/Blue ratio (NB), NIR/Green ratio (NG), NIR/Red ratio (NR), } \\
\text { NIR1/Blue ratio (N1B), NIR1/Green ratio (N1G), NIR1/Red ratio (N1R), } \\
\text { NIR1/Red edge ratio (N1RE), NIR2/Blue ratio (N2B), NIR2/Green ratio } \\
\text { (N2G), NIR2/Red ratio (N2R), NIR2/Red edge ratio (N2RE), NIR2/NIR1 } \\
\text { ratio (N2N1), SW1/Blue ratio (S1B), SW1/Green ratio (S1G), SW1/Red } \\
\text { ratio (S1R), SW1/NIR ratio (S1N), SW2/Blue ratio (S2B), SW2/Green ratio } \\
\text { (S2G), SW2/Red ratio (S2R), SW2/NIR ratio (S2N), SW2/SW1 ratio (S2S1) }\end{array}$ & \\
\hline $\begin{array}{l}\text { Vegetation indices and bare } \\
\text { soil indices }\end{array}$ & $\begin{array}{l}\text { Normalized Difference Vegetation Index (NDVI), Normalized Difference } \\
\text { Green Index (NDVIg)Simple Ratio (SR), Transformed Spectral Index (TVI), } \\
\text { Green Chlorophyll Index (CIg), Soil Adjusted Vegetation Index (SAVI), } \\
\text { Atmospherically Resistant Vegetation Index (ARVI), Crust Index (CI), } \\
\text { Modified Chlorophyll Absorption in Reflectance Index (MCARI), Red-edge } \\
\text { Chlorophyll Index (CIr), Normalized Difference Red-edge Index (NDVIr), } \\
\text { Transformed Chlorophyll Absorption in Reflectance Index (TCARI), } \\
\text { Moisture Stress Index (MSI), Normalized Difference Water Index (NDWI), } \\
\text { Mid-infrared Index (MidIR), Bare soil index (BSI), Normalized Difference } \\
\text { Soil Index (NDSI), At-satellite brightness temperature for band 10 } \\
(10.30-11.30 \mu \mathrm{m}),(\mathrm{T} 1)(\mathrm{Unit}: \mathrm{K}) \text {, At-satellite brightness temperature for } \\
\text { band } 11(11.50-12.50 \mu \mathrm{m}),(\mathrm{T} 2) \text { (Unit: K) }\end{array}$ & $\begin{array}{l}\text { (Rouse et al., 1974), (Gitelson et al., 1996), (Cohen, 1991), (Nellis } \\
\text { and Briggs, 1992), (Gitelson et al., 2005), (Qi et al., 1994), (Kaufman } \\
\text { and Tanré, 1996), (Karnieli, 1997), (Daughtry et al., 2000), (Gitelson } \\
\text { et al., 2005), (Gitelson and Merzlyak, 1994; Sims and Gamon, 2002), } \\
\text { (Haboudane et al., 2002), (Rock et al., 1986), (Gao, 1996), (Musick } \\
\text { and Pelletier, 1988), (Rikimaru and Miyatake, 1997), (Rogers and } \\
\text { Kearney, 2004) }\end{array}$ \\
\hline Topographic attributes & $\begin{array}{l}\text { Elevation (Elevation) (Unit: m), Aspect (Aspect) (Unit: Degree), Flow } \\
\text { Accumulation (FlowAccu), Flow Direction (FlowDir), Slope (Slope) (Unit: } \\
\text { Degree) }\end{array}$ & \\
\hline Geographic attributes & X coordinate (Unit: $\mathrm{m}$ ), Y coordinate (Unit: $\mathrm{m}$ ) & \\
\hline Principal component & $\begin{array}{l}\text { The first principal component score (PC1), The second principal component } \\
\text { score (PC2), The third principal component score (PC3), The fourth } \\
\text { principal component score (PC4), The fifth principal component score } \\
\text { (PC5) }\end{array}$ & \\
\hline
\end{tabular}

Table 3

Description of soil TN at $0-15 \mathrm{~cm}$.

\begin{tabular}{|c|c|c|c|c|c|c|c|c|c|c|c|}
\hline Soil property & Data type & $\mathrm{N}$ & Mean & Median & SD & Min & Max & Range & Skew & Kurtosis & $\mathrm{CV}$ \\
\hline \multirow[t]{3}{*}{ Total nitrogen $\left(\mathrm{mg} \mathrm{kg}^{-1}\right)$} & Total & 259 & 513.95 & 487.15 & 186.32 & 165.53 & 1181.66 & 1016.13 & 0.59 & 0.14 & 0.36 \\
\hline & Calibration & 180 & 513.53 & 486.69 & 190.87 & 165.53 & 1181.66 & 1016.13 & 0.63 & 0.17 & 0.37 \\
\hline & Validation & 79 & 514.92 & 487.15 & 176.69 & 205.63 & 1059.05 & 853.42 & 0.47 & -0.12 & 0.34 \\
\hline
\end{tabular}

Abbreviations: N, number of samples; SD, standard deviation; CV, coefficient of variation.

(MS) and pansharpened (PAN) remote sensing images; 3) analyzed the relationships between PAN and MS spectral indices and soil TN; 4) developed some soil TN prediction models using the Random Forest method by incorporating the PAN spectral indices; 5) explored the effects of image pansharpening on soil TN prediction models.

\section{Materials and methods}

\subsection{Description of the study area}

The study area is a smallholder village called Masuti with an area of $40 \mathrm{~km}^{2}$. It is located in Bijarpur district, Karnataka State, South India. The climate of Bijarpur district is semi-arid with average annual rainfall of $553 \mathrm{~mm}$. The temperature of the Bijarpur district is between $40^{\circ} \mathrm{C}$ to $42^{\circ} \mathrm{C}$ in the summer, and $15^{\circ} \mathrm{C}$ to $20^{\circ} \mathrm{C}$ in winter. The major soil type in the north of Masuti is Entisol, and the major soil type in the south of the Masuti is Vertisol. Two dams were built in the north central part of the village. An irrigation canal was located in the southwestern area of the village. In Masuti, $80 \%$ of the farmlands were irrigated using wells. Sorghum (Sorghum bicolar), tomato (Lycopersicon esculentum var. esculentum) and onion (Allium cepa) were three major crops in dry season. Cotton (Gossypium hirsutum), rice (Oryza sativa) and maize (Zea mays) were major crops in rainy season.

\subsection{Soil data}

The village boundary of Masuti was obtained from the International Crops Research Institute for the Semi-Arid Tropics (ICRISAT) before soil sampling. The soil of Masuti was divided into four classes (green, dark, light, and intermediate areas) using the unsupervised classification algorithm implemented in the ERDAS 2011 software (Earth Resource Data Analysis System Inc., Atlanta, GA). Based on these four classes of soil, a stratified random sampling design was created in ArcMap 10 using the "SamplingTool_10" (NOAA/Biogeography Branch, 2012) addin. The surface soil samples $(0-15 \mathrm{~cm})$ at 259 points were collected in Masuti from February to March 2013 by ICRISAT and the University of Florida team (Fig. 1). Each soil sampling location was measured by a Differential Global Positioning System (DGPS) with sub-meter accuracy (Trimble Navigation Ltd., Sunnyvale, California, USA). GPS post-correction was performed by Aimil Ltd. in Hyderabad, India. Land use, topographic condition, crop types, and $\mathrm{x}$ and $\mathrm{y}$ coordinates, were documented at each sampling point. Each collected soil sample was analyzed for total nitrogen (TN) (Krom, 1980). TN was reported on a concentration basis $\left(\mathrm{mg} \mathrm{kg}^{-1}\right)$. 


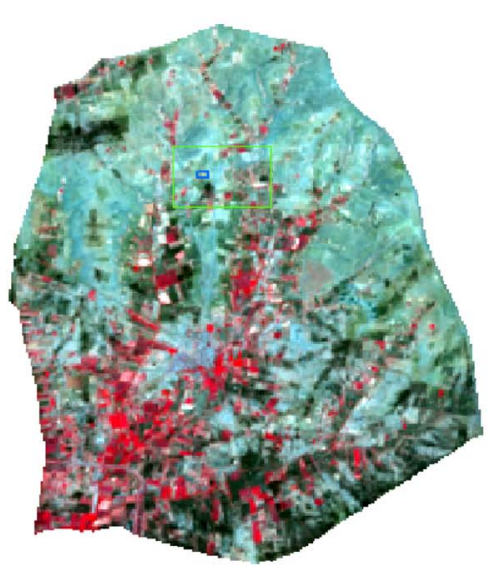

(A)

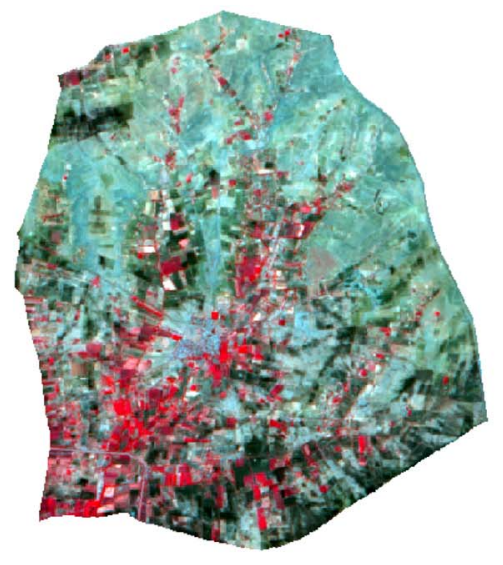

(B) (GS) PAN Landsat 8 image; (D) IntensityHue-Saturation (IHS) PAN Landsat 8 image.

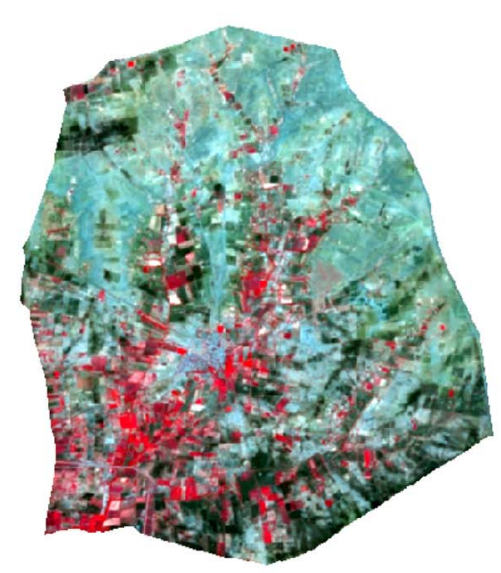

(C)

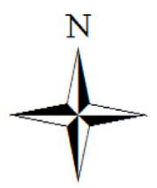

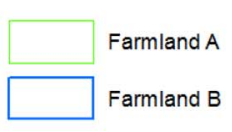

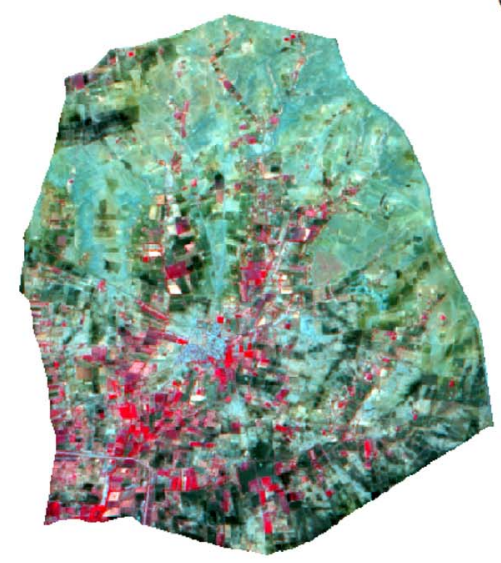

0
1.5

(D)

\subsection{Remote sensing data}

\subsubsection{Remote sensing data collection}

Multispectral remote sensing products such as a WorldView-2 image (acquisition date: 2011-2-28), a Pleiades-1A image (acquisition date: 2013-3-3), and two Landsat 8 images (acquisition date: 2013-4-20; 2013-5-22) in Masuti were acquired (Table 1). The Advanced Spaceborne Thermal Emission and Reflection Radiometer (ASTER) digital elevation model (DEM) was also collected from the United States Geological Survey (USGS) website (http://earthexplorer.usgs.gov/).

\subsubsection{Image pansharpening}

We fused the panchromatic band $(0.5 \mathrm{~m})$ and multispectral bands ( $2 \mathrm{~m}$ ) of the WorldView-2 and Pleiades-1A as well as, the panchromatic band $(15 \mathrm{~m})$ and multispectral bands $(30 \mathrm{~m})$ of the Landsat 8 into pansharpened images of Masuti. Three major image pansharpening techniques including intensity-hue-saturation (IHS) (Carper, 1990; Chavez et al., 1991), Gram-Schmidt (GS) (Laben and Brower, 2000), and Brovey (Vrabel, 2000) methods were utilized to perform the image pansharpening. Image pansharpening was performed in ENVI 5.0 software (Research System Inc.; Boulder, CO, USA).

\subsubsection{Remote sensing data processing}

All the remote sensing images were transformed to the Universal Transverse Mercator (UTM) map projection (Zone: 43 N; Datum: World
Geographic System, WGS 84). After applying radiometric calibration to convert the digital numbers of the remote sensing images to spectral radiance images, atmospheric correction was performed to transform the spectral radiance images to surface reflectance images. The Fast Line-of-Site Atmospheric Analysis of Spectral Hypercubes (FLAASH) package in ENVI 5.0 software (Research System Inc.; Boulder, CO, USA) was utilized to perform the atmospheric correction. Geometric correction was applied to all the images using 10 control points surveyed by Trimble GeoExplorer Mapping Grade GPS and post processed to a submeter accuracy. The Root Mean Square Error (RMSE) for each control point was smaller than 0.5 pixel.

\subsubsection{Environmental variable extraction}

Multiple spectral indices were extracted from MS and PAN Landsat 8, WorldView-2 and Pleiades-1A images. Those spectral indices include individual band reflectance; band ratios; near infrared-related spectral indices such as Normalized Difference Vegetation Index (NDVI) (Rouse et al., 1974) and Atmospherically Resistant Vegetation Index (ARVI) (Kaufman and Tanré, 1996); red edge-related spectral indices such as Normalized Difference Red-edge Index (NDVIr) (Gitelson and Merzlyak, 1994; Sims and Gamon, 2002); short wavelength-related spectral indices such as Normalized Difference Water Index (NDWI) (Gao, 1996), and thermal wavelength-related spectral indices such as at-satellite brightness temperature for band 10 from Landsat $8(10.30-11.30 \mu \mathrm{m})$ (K) (T1). A principal component analysis (PCA) was performed to 

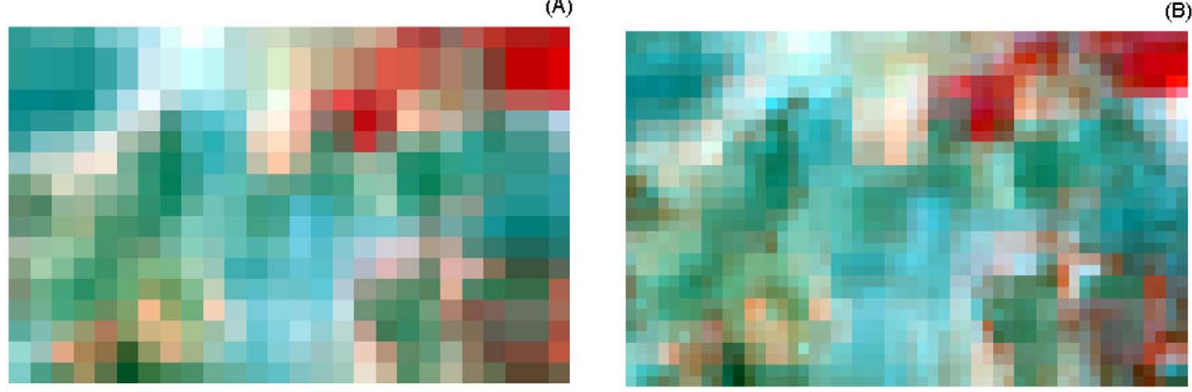

(C)
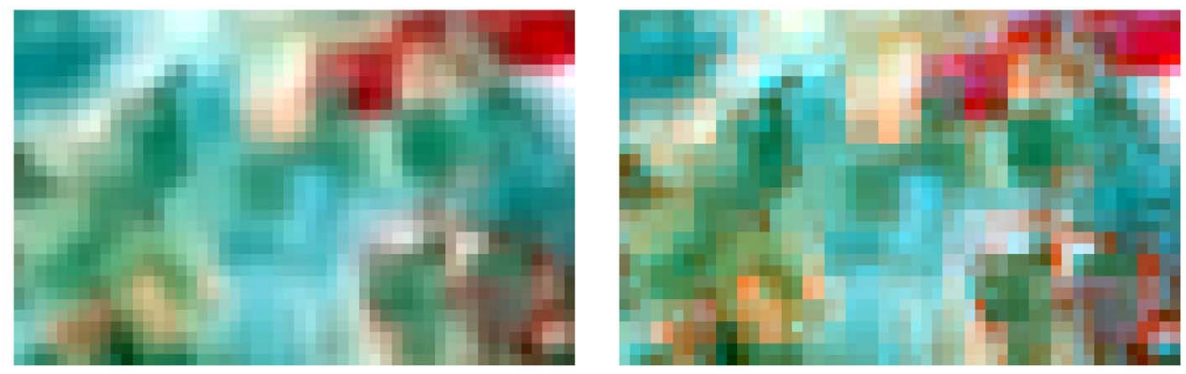

(B)

Fig. 3. MS and PAN Landsat 8 images in Farmland $\mathrm{A}$ of Masuti. (A) MS Landsat 8 image; (B) Brovey PAN Landsat 8 Image; (C) GS PAN Landsat 8 image; (D) IHS PAN Landsat 8 image. derive principal component (PC) scores for the multispectral images. Topographic attributes such as elevation (m), slope (degree), and aspect (degree) were derived from ASTER DEM. All environmental variables used in this research are shown in Table 2.

\subsection{Statistical analysis}

\subsubsection{Relevant variable identification}

The Boruta method proposed by Rudnicki and Kursa (2010) is based on the Random Forest (RF) algorithm. The Boruta algorithm can cope with redundancy and collinearity between the variables (Hitziger and Ließ, 2014; Schlund et al., 2014). In this research, the Boruta algorithm can identify the spectral indices which are relevant with soil TN from a spectral library and assign an important score to each relevant variable. Eight spectral libraries were utilized including Spectral Library 1 (SL1): MS Landsat 8 spectral indices and DEM Derivatives (DDs); SL2: MS and Brovey Landsat 8 spectral indices and DDs; SL3: MS and GS Landsat 8 spectral indices and DDs; SL4: MS and IHS Landsat 8 spectral indices and DDs; SL5: MS WorldView-2/Pleiades-1A spectral indices and DDs; SL6: MS and Brovey WorldView-2/Pleiades-1A spectral indices and DDs; SL7: MS and GS WorldView-2/Pleiades-1A spectral indices and DDs; SL8: MS and IHS WorldView-2/Pleiades-1A spectral indices and DDs. The Boruta algorithm was applied to each spectral library to identify the spectral indices which are relevant variables with soil TN.

\subsubsection{Modeling soil TN using the random forest method}

Eight soil TN models were developed to explore the effect of image sharpening on soil TN models. Spectral indices identified as relevant variables from eight spectral libraries were included as environmental variables into Model NLTM (SL1), NLTB (SL2), NLTG (SL3), NLTI (SL4), NWPM (SL5), NWPB (SL6), NWPG (SL7), and NWPI (SL8). Multiple R packages such as "Boruta", "randomForest", "rgdal", "raster" were utilized to build soil TN prediction models and map soil TN.

\subsection{Validation of soil TN prediction models}

All the soil sample points were split into a calibration $(70 \%$, $n=180)$ and a validation sets $(30 \%, n=79)$ using "caret" package in $\mathrm{R}$ software. The Kolmogorov-Smirnov test was applied on the soil calibration and validation sets to ensure they have the same distribution. The adjusted coefficient of determination (Adj $\mathrm{R}^{2}$ ), root mean squared error (RMSE), residual prediction deviation (RPD) (Williams, 2001), and ratio of performance to inter-quartile distance (RPIQ) (Williams and Norris, 1987) were used to compare different soil TN models.

\section{Results}

\subsection{Descriptive analysis of soil $T N$}

Table 3 showed the descriptive analysis of soil TN at $0-15 \mathrm{~cm}$. TN had a mean of $513.95 \mathrm{mg} \mathrm{kg}^{-1}$, a medium of $487.15 \mathrm{mg} \mathrm{kg}^{-1}$, and a range of $1016.13 \mathrm{mg} \mathrm{kg}^{-1}$. TN of soil samples showed positive skewed distribution. Similarities between the calibration, validation, and whole datasets suggested that the calibration and validation datasets of TN were representative.

\subsection{Visual analysis of multispectral and pansharpened images}

Fig. 2 illustrates the MS and PAN Landsat 8 images in Masuti. Three PAN Landsat 8 images $(15 \mathrm{~m})$ show a stronger capability to depict field block, irrigation canals, roads, buildings, vegetation, soils and other landscape features compared with MS Landsat 8 images. Fig. 3 shows the three PAN Landsat 8 images of a farmland (Farmland A) in the study area demonstrating their advantages in characterizing the landscape over the MS Landsat 8 image. However, PAN Landsat 8 images still have relatively coarse spatial resolution $(15 \mathrm{~m})$. Fine ground features such as farmland, houses, and roads cannot be explicitly recognized in all four figures in Fig. 3.

Fig. 4 shows the MS and PAN WorldView-2 images of Masuti. Due to the fine spatial resolution of these images, it is difficult to distinguish 


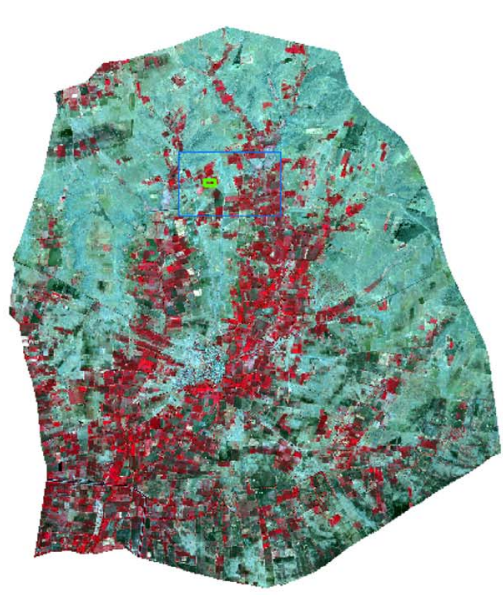

(A)

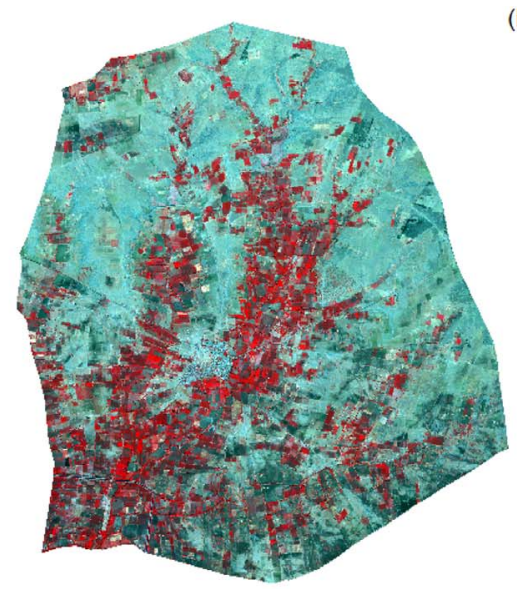

(C)

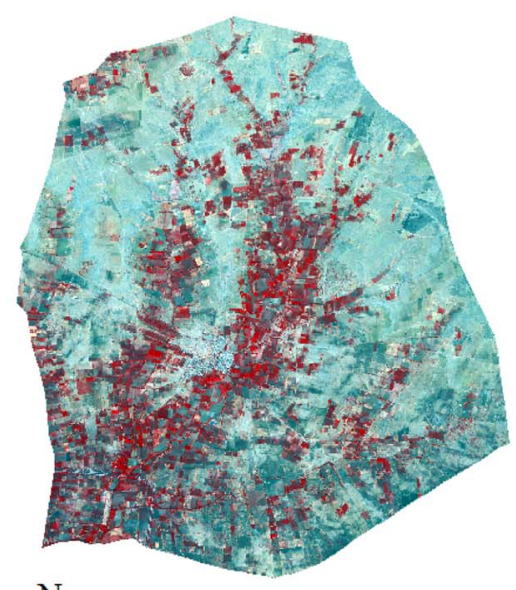

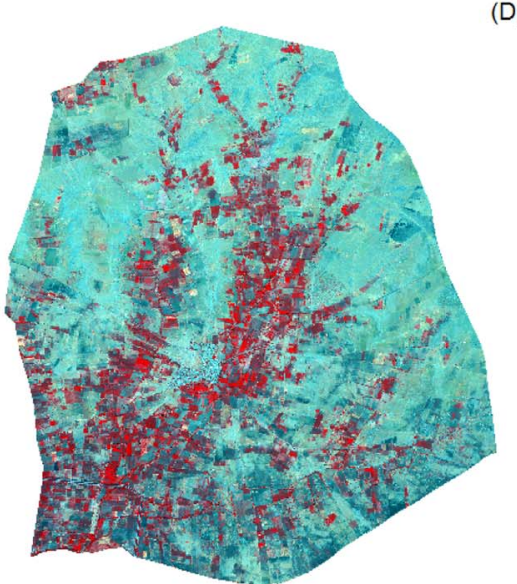

(D)

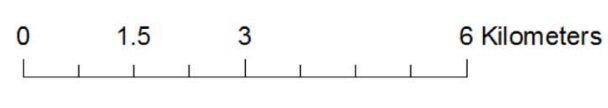

Fig. 4. MS and PAN WorldView-2 images of Masuti. (A) MS WorldView-2 image; (B) Brovey WorldView-2 image; (C) GS WorldView-2 image; (D) IHS WorldView-2 image. the differences among them. All the images show strong capability to identify the ground features. In general, more crops were planted in the southwestern area of the village. Large areas of bare soil existed in the northern and eastern areas of the village. Fig. 5 demonstrates four WorldView-2 images in another farmland area of the village (Farmland B). The outlines of a water reservoir and field blocks in the Brovey and IHS PAN WorldView-2 images are still fuzzy and not sharp enough. The GS PAN WorldView-2 images can clearly display the ridge, the contrast of plant and soil in the sparsely vegetated land (southwestern area of Farmland B), the outline of the water reservoir, the roads between different field blocks, the vegetation variations in medium vegetated areas (south central of Farmland B) and densely vegetated areas (eastern area of Farmland B).

\subsection{Effect of image pansharpening on soil TN models}

\subsubsection{Relationship between soil TN and MS/PAN Landsat 8 spectral indices}

Atmospherically Resistant Vegetation Index (ARVI), Crust Index (CI), and Normalized Difference Water Index (NDWI) from the MS Landsat 8 images had relatively strong positive correlations with TN (Table 4). In contrast, the band ratio of red to green (RG), band ratio of red to blue (RB) and some short wavelength infrared (SWIR) band-related spectral indices such as bare soil index (BSI) and SWIR band 2 spectral reflectance (SWIR2) had relatively strong negative linear correlations with soil TN. The spectral behavior of the PAN Landsat 8 spectral indices is similar to MS Landsat 8 spectral indices. ARVI and CI from MS and PAN Landsat 8 images all had relatively strong positive linear correlations with soil TN. RB, RG, and red reflectance from MS and PAN Landsat 8 images all had relatively strong negative linear correlations with soil TN. Table 5 shows the environmental variables identified as relevant variables with soil TN by the Boruta algorithm. Some SWIR and TIR related spectral indices such as ratio of SWIR band 2 to SWIR band 1 (LTaS2S1), mid-infrared index (LTaMidIR), and atsatellite brightness temperature for thermal band $1(10.30-11.30 \mu \mathrm{m})$ (LTaT1) were also identified as relevant variables with TN (Table 5). Six GS PAN spectral indices from Landsat 8 were identified as relevant variables, while only two Brovey PAN spectral indices and one IHS PAN spectral index were identified as relevant variables with soil TN.

\subsubsection{Relationship between soil TN and MS/PAN WorldView-2 and Pleiades-1A spectral indices}

The spectral behavior of the three PAN WorldView-2 and Pleiades$1 \mathrm{~A}$ images is also similar to the MS WorldView-2 and Pleiades-1A. The visible band reflectance values, band ratios between visible band reflectances, and CI from the MS and PAN WorldView-2 and Pleiades-1A had relatively strong negative correlations with TN (Table 6). More spectral indices from the IHS Pleiades-1A and WorldView-2 images were identified as relevant variables with soil TN than those from Brovey and GS Pleiades-1A and WorldView-2 images. The GB, RB, and $\mathrm{CI}$ indices from three PAN Pleiades-1A images were all identified as relevant variables (Table 7). Some new additional band reflectance and 
(A)
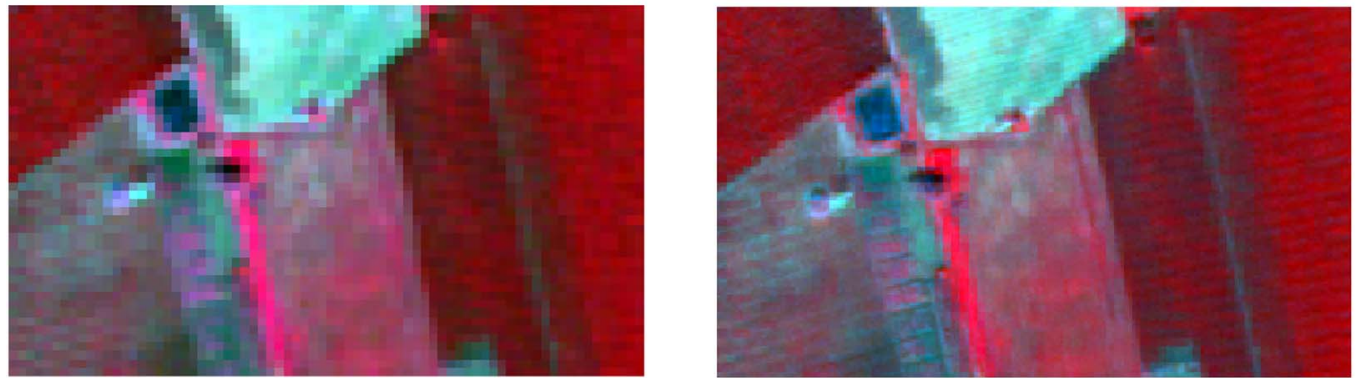

(C)
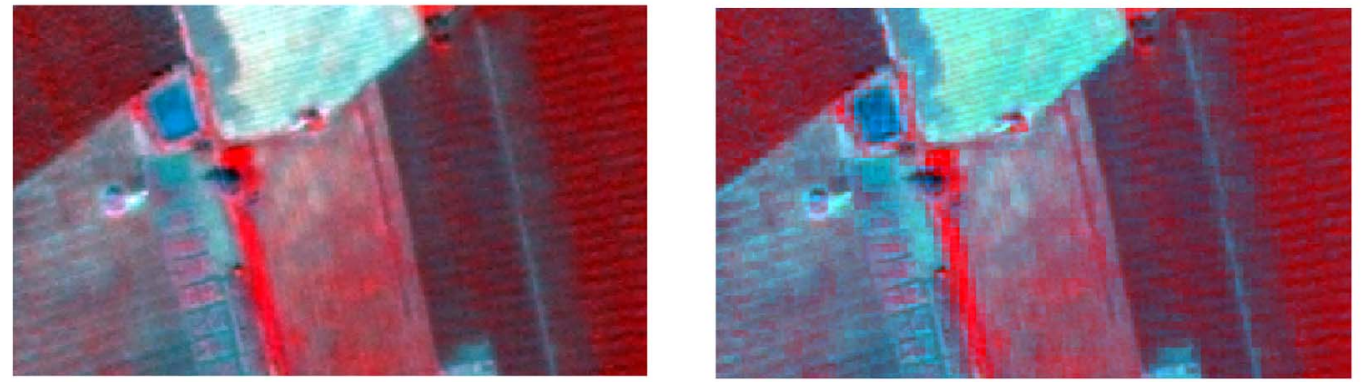

(D)

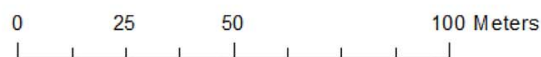

100 Meters

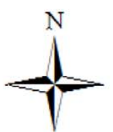

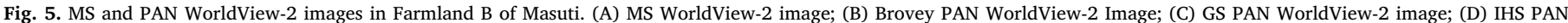
WorldView-2 image.

Table 4

Linear correlations between soil TN and spectral indices from PAN and MS Landsat 8 images at 259 soil sampling sites (0-15 cm).

\begin{tabular}{|c|c|c|c|c|c|c|c|}
\hline \multicolumn{2}{|c|}{ MS spectral indices } & \multicolumn{2}{|c|}{ MS and Brovey spectral indices } & \multicolumn{2}{|c|}{ MS and GS spectral indices } & \multicolumn{2}{|c|}{ MS and IHS spectral indices } \\
\hline Variable & $\mathrm{R}$ & Variable & $\mathrm{R}$ & Variable & $\mathrm{R}$ & Variable & $\mathrm{R}$ \\
\hline LTaARVI & 0.481 & LTaARVI & 0.481 & LTaGRG & -0.485 & LTaARVI & 0.481 \\
\hline LTaRG & -0.481 & LTaRG & -0.481 & LTaARVI & 0.481 & LTaRG & -0.481 \\
\hline LTaBSI & -0.478 & LTaBRG & -0.479 & LTaRG & -0.481 & LTaBSI & -0.478 \\
\hline LTbRG & -0.465 & LTaBSI & -0.478 & LTaBSI & -0.478 & LTaIRG & -0.466 \\
\hline LTbCI & 0.454 & LTbRG & -0.465 & LTbGRG & -0.474 & LTbRG & -0.465 \\
\hline LTbRB & -0.454 & LTbBRG & -0.464 & LTaGARVI & 0.472 & LTbIRG & -0.461 \\
\hline LTaCI & 0.450 & LTbBCI & 0.461 & LTbGCI & 0.468 & LTbICI & 0.457 \\
\hline LTaRB & -0.450 & LTbBRB & -0.461 & LTbGRB & -0.468 & LTbIRB & -0.457 \\
\hline LTbBSI & -0.447 & LTaBARVI & 0.457 & LTbRG & -0.465 & LTbCI & 0.454 \\
\hline LTaRed & -0.442 & LTbCI & 0.454 & LTaGCI & 0.463 & LTbRB & -0.454 \\
\hline LTbARVI & 0.441 & LTbRB & -0.454 & LTaGRB & -0.463 & LTaICI & 0.452 \\
\hline LTbRed & -0.441 & LTbBRed & -0.453 & LTbGARVI & 0.456 & LTaIRB & -0.452 \\
\hline LTaSWIR2 & -0.432 & LTaBCI & 0.453 & LTbCI & 0.454 & LTaCI & 0.450 \\
\hline LTaNDWI & 0.416 & LTaBRB & -0.453 & LTbRB & -0.454 & LTaRB & -0.450 \\
\hline LTaMSI & -0.416 & LTaCI & 0.450 & LTbGRed & -0.453 & LTaIARVI & 0.448 \\
\hline
\end{tabular}

Nomenclature of the variable in Table 4: remote sensing image (abbreviation in Table 1) + spectral index (abbreviation in Table 2).

Abbreviations: R, Spearman's rank correlation coefficient; GS, Gram-Schmidt; IHS, intensity, hue and saturation.

band ratios such as yellow and red edge band reflectance values, and band ratio of NIR band 2 to red edge band (N2RE) from the MS WorldView-2 image were also identified as relevant variables with soil TN.

\subsubsection{Spatial pattern of TN based on different soil prediction models}

Eight random forest models were utilized to predict soil TN. Detailed characteristics of eight soil prediction models are shown in
Table 8. In Fig. 6, TN prediction maps produced by PAN/MS Landsat 8based soil TN models (models NLTB, NLTG, NLTI) display relatively higher spatial heterogeneity of TN variation compared with the map produced by MS Landsat 8-based soil TN model (model NLTM). TN prediction map based on model NLTG (Fig. 6 (C)) depicts some high TN patterns in northeastern areas of the village, which the other three maps do not display. Four maps in Fig. 6 show similar TN spatial pattern.

Fig. 7 compares the TN prediction maps based on Landsat 8 images 
Table 5

Importance score (mean Z-score) between soil TN and relevant variables from PAN and MS Landsat 8 images.

\begin{tabular}{|c|c|c|c|c|c|c|c|}
\hline \multicolumn{2}{|c|}{ MS spectral indices } & \multicolumn{2}{|c|}{ MS and Brovey spectral indices } & \multicolumn{2}{|c|}{ MS and GS spectral indices } & \multicolumn{2}{|c|}{ MS and IHS spectral indices } \\
\hline Variable & MeanZ & Variable & MeanZ & Variable & MeanZ & Variable & MeanZ \\
\hline LTaARVI & 11.98 & LTaARVI & 11.26 & LTaARVI & 11.32 & LTaARVI & 11.50 \\
\hline LTbRG & 11.29 & LTbRG & 10.92 & LTbRG & 11.04 & LTbRG & 11.14 \\
\hline LTaBSI & 10.12 & LTaBSI & 9.76 & LTaBSI & 10.20 & LTaBSI & 9.74 \\
\hline LTbRB & 8.77 & LTbRB & 7.94 & LTbRB & 8.04 & LTbRB & 8.24 \\
\hline LTbCI & 7.79 & LTbCI & 7.18 & LTaGRG & 7.83 & LTbCI & 7.40 \\
\hline LTaRG & 7.75 & LTaRG & 6.78 & LTaT1 & 7.40 & LTaRG & 6.91 \\
\hline LTaS2S1 & 7.53 & LTaT1 & 6.67 & LTaS2S1 & 7.29 & LTaMidIR & 6.75 \\
\hline LTaMidIR & 7.47 & LTbBRed & 6.65 & LTbCI & 7.19 & LTaS2S1 & 6.71 \\
\hline LTaT1 & 7.14 & LTaS2S1 & 6.63 & LTaMidIR & 7.08 & LTaT1 & 6.71 \\
\hline LTbRed & 6.76 & LTaMidIR & 6.47 & LTaRG & 6.96 & LTaINIR & 6.42 \\
\hline LTbMidIR & 6.53 & LTbRed & 6.25 & LTbGSR & 6.88 & LTbRed & 6.38 \\
\hline LTbS2S1 & 6.52 & LTbMidIR & 5.79 & LTbGTVI & 6.80 & LTbS2S1 & 5.62 \\
\hline \multirow[t]{6}{*}{ LTbS2B } & 5.90 & LTaBNIR & 5.74 & LTbGRG & 6.80 & LTbMidIR & 5.54 \\
\hline & & LTbS2S1 & 5.70 & LTbRed & 6.75 & & \\
\hline & & & & LTbGNDVI & 6.55 & & \\
\hline & & & & LTbS2S1 & 6.24 & & \\
\hline & & & & LTbMidIR & 6.21 & & \\
\hline & & & & LTaGARVI & 5.98 & & \\
\hline
\end{tabular}

Nomenclature of the variable in Table 5: remote sensing image (abbreviation in Table 1) + spectral index (abbreviation in Table 2).

Table 6

Linear correlations between soil TN and spectral indices from PAN and MS WorldView-2 and Pleiades-1A images at 259 soil sampling sites (0-15 cm).

\begin{tabular}{|c|c|c|c|c|c|c|c|}
\hline \multicolumn{2}{|c|}{ MS spectral indices } & \multicolumn{2}{|c|}{ MS and Brovey spectral indices } & \multicolumn{2}{|c|}{ MS and GS spectral indices } & \multicolumn{2}{|c|}{ MS and IHS spectral indices } \\
\hline Variable & $\mathrm{R}$ & Variable & $\mathrm{R}$ & Variable & $\mathrm{R}$ & Variable & $\mathrm{R}$ \\
\hline WVCI & 0.450 & PLBCI & 0.463 & PLGCI & 0.462 & PLICI & 0.460 \\
\hline WVRB & -0.450 & PLBRB & -0.463 & PLGRB & -0.462 & PLIRB & -0.460 \\
\hline PLRG & -0.440 & PLBRG & -0.459 & PLGRG & -0.455 & PLIRG & -0.458 \\
\hline PLCI & 0.437 & WVCI & 0.450 & WVCI & 0.450 & WVCI & 0.450 \\
\hline PLRB & -0.437 & WVRB & -0.450 & WVRB & -0.450 & WVRB & -0.450 \\
\hline PLPCA3 & 0.424 & PLRG & -0.440 & PLRG & -0.440 & PLRG & -0.440 \\
\hline PLRed & -0.424 & PLCI & 0.437 & PLCI & 0.437 & PLCI & 0.437 \\
\hline WVRG & -0.417 & PLRB & -0.437 & PLRB & -0.437 & PLRB & -0.437 \\
\hline WVRed & -0.405 & PLBRed & -0.433 & PLGRed & -0.433 & WVICI & 0.429 \\
\hline WVYellow & -0.402 & PLPCA3 & 0.424 & WVGCI & 0.426 & WVIRB & -0.429 \\
\hline PLGB & -0.397 & PLRed & -0.424 & WVGRB & -0.426 & WVIRG & -0.425 \\
\hline PLBlue & -0.384 & WVBCI & 0.422 & WVGRG & -0.426 & PLPCA3 & 0.424 \\
\hline WVN2RE & 0.381 & WVBRB & -0.422 & PLPCA3 & 0.424 & PLRed & -0.424 \\
\hline WVARVI & 0.379 & WVBRG & -0.420 & PLRed & -0.424 & PLIRed & -0.418 \\
\hline PLARVI & 0.376 & WVRG & -0.417 & WVRG & -0.417 & WVRG & -0.417 \\
\hline
\end{tabular}

Nomenclature of the variable in Table 6: remote sensing image (abbreviation in Table 1) + spectral index (abbreviation in Table 2).

Abbreviations: MeanZ, importance score; GS, Gram-Schmidt; IHS, intensity, hue and saturation.

in Farmland A. MS/PAN Landsat 8-based TN prediction maps (Fig. 7 (B), (C) and (D)) all had higher spatial resolution than MS Landsat 8based TN prediction map (Fig. 7 (A)) when compared visually. TN prediction map based on model NLTG (Fig. 7 (C)) displays the most heterogeneous TN distribution. For example, while there are some high TN patterns in the north central area of Farmland A in Fig. 7 (C), these TN patterns are not predicted in other maps in Fig. 7. In general, the incorporation of three PAN Landsat 8 spectral indices brought in somewhat spatial resolution enhancement from visual interpretation.

Fig. 8 shows four TN maps based on WorldView- 2 and Pleiades-1A spectral indices. Crops were planted densely in the southern area of the village, where Vertisols are the main soil type. The sugarcane land in the southwestern area of the village had relatively high TN. In addition, the irrigation canal built in the southwestern area of the village may also bring more water to the soil in this area. It is possible the relatively higher soil moisture in the southwestern area contributes to the relatively higher soil TN in this area. The soil in the northern area of the village is mainly Entisols, where a few plots of crops were planted sparsely. Large areas in the northern and eastern areas of the village had relatively low TN. Four soil TN maps in Fig. 8 show the spatial pattern of soil TN was fragmented and mosaic with high variations in the small farmland. The linear pattern of TN displayed the low TN in the road, the dot pattern of TN demonstrated the intricate variations of $\mathrm{TN}$ in the field block, and the polygon pattern of TN showed the gradients of TN in different field blocks. Fig. 9 compares four TN prediction maps in Farmland B. In general, four soil TN maps based on WorldView2 and Pleiades-1A have capability to depict the intricate difference of soil TN in Farmland B. TN distribution in Fig. 9 (B), (C) and (D) can portray the subtle spatial variation of TN in $0.5 \mathrm{~m}$ spatial resolution.

\subsubsection{Accuracy measurement of soil TN prediction models}

Table 8 showed accuracy measurement of soil TN models based on MS and PAN Landsat 8, WorldView-2 and Pleiades-1 images. Three soil TN prediction models incorporating PAN and MS Landsat 8 spectral indices had stronger predictive capability than the soil TN prediction model only incorporating MS Landsat 8 spectral indices. The three soil TN prediction models incorporating PAN and MS WorldView-2 and Pleiades-1A spectral indices also had slightly stronger predictive capability than the soil TN prediction model only incorporating MS WorldView-2 and Pleiades-1A spectral indices. MS/GS Landsat 8-based 
Table 7

Importance score (mean Z-score) between TN and relevant variables from MS and PAN WorldView-2 and Pleiades-1A images.

\begin{tabular}{|c|c|c|c|c|c|c|c|}
\hline \multicolumn{2}{|c|}{ MS spectral indices } & \multicolumn{2}{|c|}{ MS and Brovey spectral indices } & \multicolumn{2}{|c|}{ MS and GS spectral indices } & \multicolumn{2}{|c|}{ MS and IHS spectral indices } \\
\hline Variable & MeanZ & Variable & MeanZ & Variable & MeanZ & Variable & MeanZ \\
\hline WVRB & 8.94 & PLBGB & 7.95 & PLGRB & 10.22 & PLIGB & 7.96 \\
\hline PLGB & 8.87 & PLBCI & 7.52 & PLGCI & 9.49 & PLPCA3 & 7.34 \\
\hline WVCI & 8.47 & WVRB & 7.25 & PLGRG & 8.45 & PLICI & 7.28 \\
\hline WVYellow & 8.07 & PLPCA3 & 7.24 & PLPCA3 & 7.38 & WVIRB & 6.98 \\
\hline PLCI & 8.00 & PLBRB & 6.91 & WVRB & 7.08 & WVRB & 6.92 \\
\hline PLRB & 7.52 & WVYellow & 6.71 & WVN2RE & 6.86 & WVICI & 6.66 \\
\hline WVN2RE & 7.05 & WVCI & 6.70 & WVCI & 6.54 & PLIRB & 6.63 \\
\hline WVRededge & 6.79 & WVN2RE & 6.58 & WVPCA3 & 6.23 & WVCI & 6.53 \\
\hline PLBlue & 6.72 & PLBNG & 6.21 & WVYellow & 6.22 & WVN2RE & 6.51 \\
\hline PLGreen & 6.37 & WVRededge & 6.20 & PLGNB & 6.19 & WVYellow & 6.48 \\
\hline WVRG & 5.87 & PLBCIg & 6.13 & PLRG & 6.09 & PLING & 6.38 \\
\hline WVGB & 5.87 & PLBNDVIg & 6.05 & WVRededge & 6.07 & PLINDVIg & 6.36 \\
\hline PLARVI & 5.82 & WVPCA3 & 6.03 & PLRB & 5.99 & PLICIg & 6.34 \\
\hline WVGreen & 5.54 & PLGB & 5.96 & PLCI & 5.61 & PLGB & 6.03 \\
\hline WVRed & 5.38 & PLCI & 5.80 & WVGRG & 5.39 & PLCI & 5.76 \\
\hline \multirow[t]{7}{*}{ PLSAVI } & 5.17 & PLBARVI & 5.65 & WVGRed & 5.20 & PLIARVI & 5.72 \\
\hline & & WVBRB & 5.61 & PLRed & 5.16 & WVRededge & 5.71 \\
\hline & & WVBCI & 5.48 & PLGRed & 5.13 & WVPCA3 & 5.47 \\
\hline & & PLRB & 5.46 & PLGGB & 5.10 & PLRB & 5.34 \\
\hline & & & & & & WVIRed & 5.16 \\
\hline & & & & & & WVGB & 4.98 \\
\hline & & & & & & PLIBlue & 4.87 \\
\hline
\end{tabular}

Nomenclature of the variable in Table 7: remote sensing image (abbreviation in Table 1) + spectral index (abbreviation in Table 2).

Abbreviations: MeanZ, importance score; GS, Gram-Schmidt; IHS, intensity, hue and saturation.

Table 8

Description of soil TN models.

\begin{tabular}{|c|c|c|c|c|c|c|}
\hline Model & Adj $R^{2}$ & RMSE (mg kg ${ }^{-1}$ ) & RPD & RPIQ & Spectral indices & Spatial resolution (m) \\
\hline NLTM & 0.43 & 131.89 & 1.27 & 2.05 & MS spectral indices in Table 5 & 30 \\
\hline NLTB & 0.45 & 131.45 & 1.28 & 2.06 & MS and Brovey spectral indices in Table 5 & 15 \\
\hline NLTG & 0.49 & 125.71 & 1.34 & 2.15 & MS and GS spectral indices in Table 5 & 15 \\
\hline NLTI & 0.46 & 129.43 & 1.30 & 2.09 & MS and IHS spectral indices in Table 5 & 15 \\
\hline NWPM & 0.41 & 137.17 & 1.21 & 1.89 & MS spectral indices in Table 7 & 2 \\
\hline NWPB & 0.43 & 135.80 & 1.24 & 1.91 & MS and Brovey spectral indices in Table 7 & 0.5 \\
\hline NWPG & 0.45 & 134.66 & 1.25 & 1.93 & MS and GS spectral indices in Table 7 & 0.5 \\
\hline NWPI & 0.44 & 134.70 & 1.25 & 1.93 & MS and IHS spectral indices in Table 7 & 0.5 \\
\hline
\end{tabular}

Nomenclature of model name in Table 8: soil property + remote sensing sensor + image type.

Soil property: $\mathrm{N}$, total nitrogen.

Remote sensing sensor: LT, Landsat 8 image; WP, WorldView-2 and Pleiades-1A images.

Image type: M, multispectral images; B, Brovey PAN images; G, Gram-Schmidt PAN images; I, Intensity-Hue-Saturation PAN images.

model NLTG had slightly higher model fit and lower prediction error (Adj $\mathrm{R}^{2}=0.49$; RMSE $=125.71 \mathrm{mg} \mathrm{kg}^{-1}$ ) than other Landsat 8-based models such as NLTB (Adj $\mathrm{R}^{2}=0.45$; RMSE $=131.45 \mathrm{mg} \mathrm{kg}^{-1}$ ) and NLTI (Adj $\mathrm{R}^{2}=0.46$; RMSE $=129.43 \mathrm{mg} \mathrm{kg}^{-1}$ ). The MS/GS WorldView-2/Pleiades-1A-based model NWPG had slightly higher model fit and lower prediction error (Adj $\mathrm{R}^{2}=0.45$; RMSE $=1.25 \mathrm{mg} \mathrm{kg}^{-1}$ ) than other WorldView-2/Pleiades-1A-based models such as NWPB (Adj $\mathrm{R}^{2}=0.43 ; \quad \mathrm{RMSE}=129.43 \mathrm{mg} \mathrm{kg}^{-1}$ ) and NWPI (Adj $\mathrm{R}^{2}=0.44$; RMSE $=129.43 \mathrm{mg} \mathrm{kg}^{-1}$ ).

\section{Discussion}

\subsection{Relationships of soil $T N$ and spectral indices from different remote sensing images}

Some visible and near infrared bands-based spectral indices such as Crust Index (CI) and ARVI had relatively strong positive correlations with soil TN. Soil crusts can help fix nitrogen (Belnap, 2002) and carbon (Beymer and Klopatek, 1991), reduce wind and water erosion of soil surfaces (McKenna Neuman et al., 1996), and retain soil moisture (Belnap and Lange, 2002). The positive correlation between CI and soil TN may suggest the importance of the soil crust in conserving soil TN in the study area. ARVI can minimize the effects of atmospheric scattering caused by aerosols in the red channel (Bannari et al., 1995). The correlation between ARVI and TN was higher than other traditional vegetation indices such as NDVI and SR in this research. Due to the multiple water absorption feature in the VNIR-SWIR spectrum region (Griffin and Burke, 2003), the increase of water content in soil may lead to the decrease of spectral reflectances. As the leaf pigments and chlorophyll absorb visible light, the relatively dense vegetated areas were prone to have smaller spectral reflectance values compared with sparsely vegetated areas. The negative correlations between soil TN and visible bands spectral reflectances may suggest that relatively wet soils were prone to contain more $\mathrm{TN}$ than relatively dry soil, and the relatively densely vegetated areas were prone to contain more $\mathrm{TN}$ than relatively sparsely vegetated areas.

The red-edge wavelength is defined as the wavelength between the red and near infrared wavelength. Red edge-based spectral indices were proven to successfully predict plant nitrogen status (Clevers and Gitelson, 2013), plant biomass (Filella and Penuelas, 1994), plant chlorophyll content (Delegido et al., 2013), and yield of agricultural crops (Curran and Catt, 1994) in various studies. Li et al. (2014) utilized the red edge-based spectral indices from hyperspectral narrow bands and WorldView-2 satellite broad bands to estimate plant nitrogen 


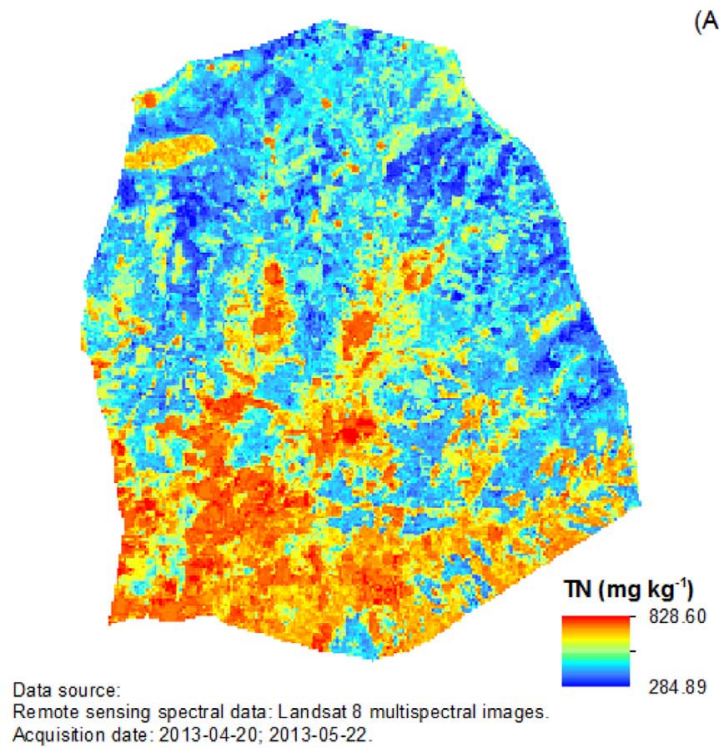

(A)

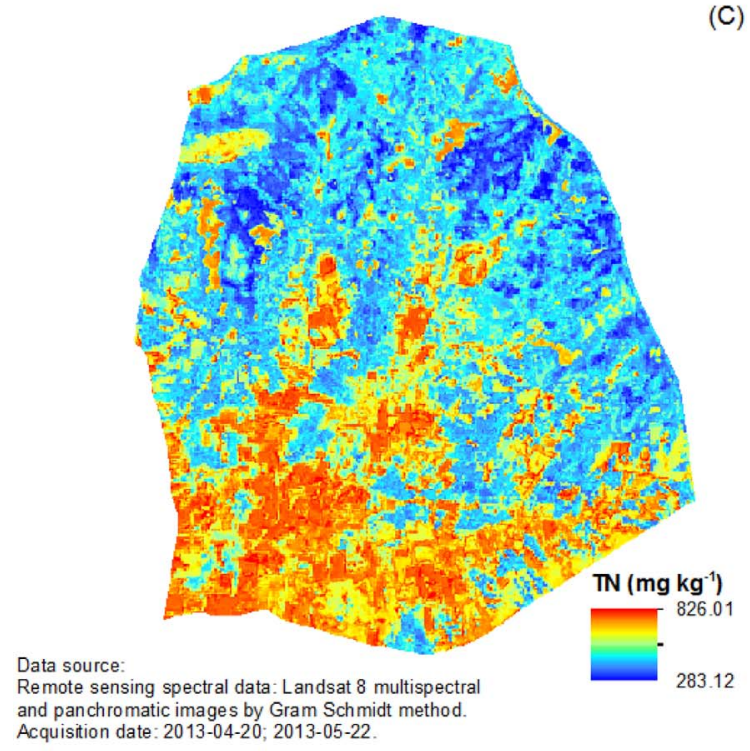

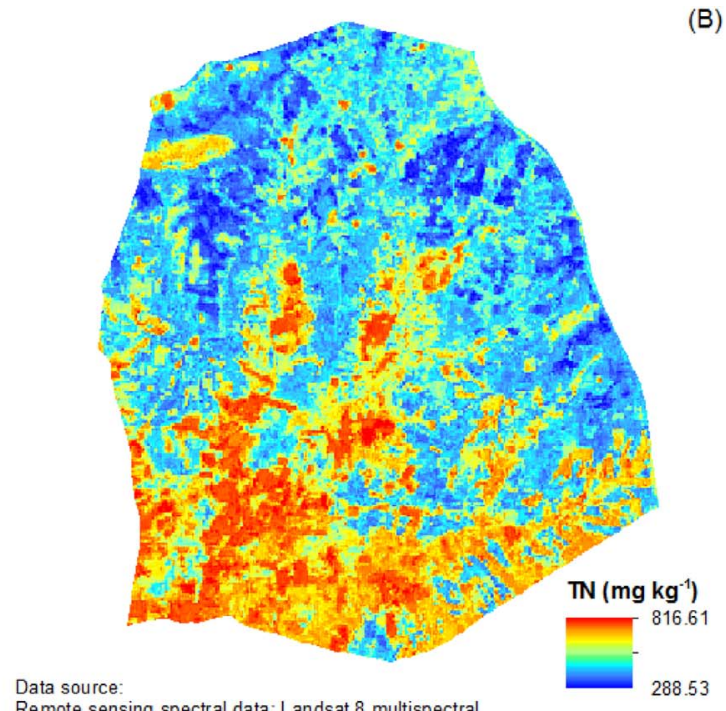

Remote sensing spectral data: Landsat 8 multispectral and panchromatic images by Brovey method

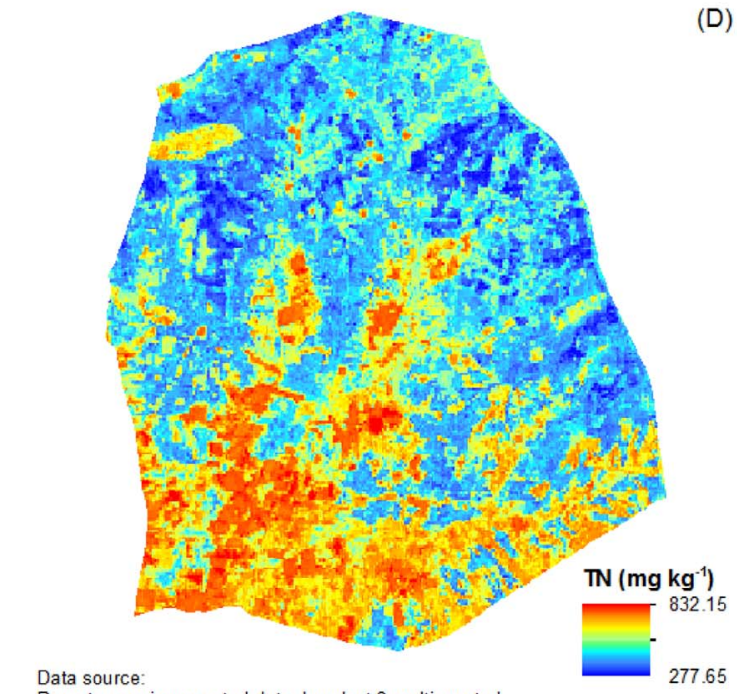

Data source:
Remote sensing spectral data: Landsat 8 multispectral and panchromatic images by $1 \mathrm{HS}$ method Acquisition date : 2013-04-20; 2013-05-22.
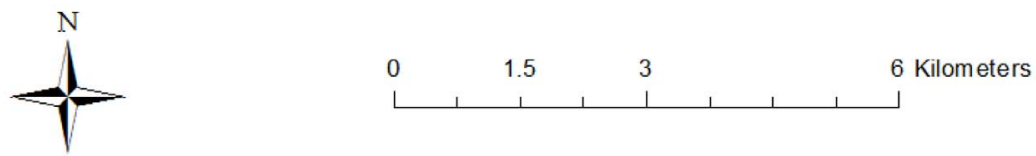

Fig. 6. Soil total nitrogen (TN) prediction at $0-15 \mathrm{~cm}$ depth in Masuti by (A) Model NLTM, (B) Model NLTB, (C) Model NLTG, (D) Model NLTI.

concentration and uptake in North China. As the red edge-based spectral vegetation indices, such as band ratio of near infrared band 2 to red edge band (WVN2RE) and red edge band reflectance (WVRededge) from WorldView-2 image were identified as relevant variables with soil TN (Table 7), it is possible that red edge-based spectral indices were important environmental variables to estimate soil nitrogen.

SWIR spectral reflectances had relatively strong negative correlations with TN. There are strong water absorption features in the SWIR bands (Chen et al., 2005), and relatively strong negative correlations between SWIR spectral reflectances and TN indicated that the areas with more water were prone to contain more TN than the areas with less water. At satellite brightness temperature from Landsat 8 images (LTaT1) was also identified as relevant variables with TN in the study area. In semi-arid and arid areas, the satellite brightness temperatures can reveal important information about the water irrigation and soil moisture (Dupigny-Giroux and Lewis, 1999). Various studies have suggested that information from TIR such as surface temperature can help monitor canopy water stress and soil moisture conditions (Holzman et al., 2014; Jones et al., 2009). As soil moisture can affect the distribution of the soil nutrients such as soil TN, the research suggested that spectral indices derived from thermal bands in Landsat 8 have potential to help predict soil TN in semi-arid agricultural land. In general, the complex interplays among vegetation, soil moisture, soil temperature, soil crust, nitrification, denitrification and anthropogenic factor may affect the spatial distribution of $\mathrm{TN}$ in the study area.

The advantages of the image pansharpening technique are not only to improve the spatial resolution, but also to retain the spectral information of multispectral images (Zhang, 2010). Some spectral indices 
(A)
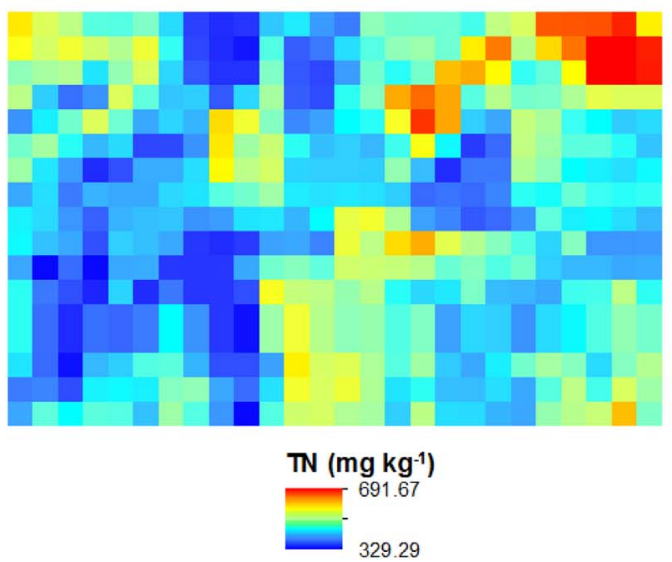

(C)
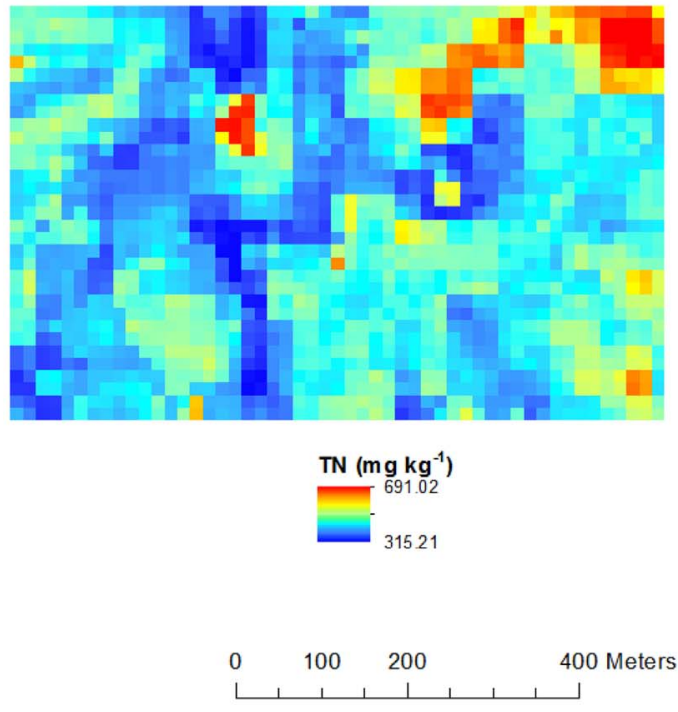

(B)

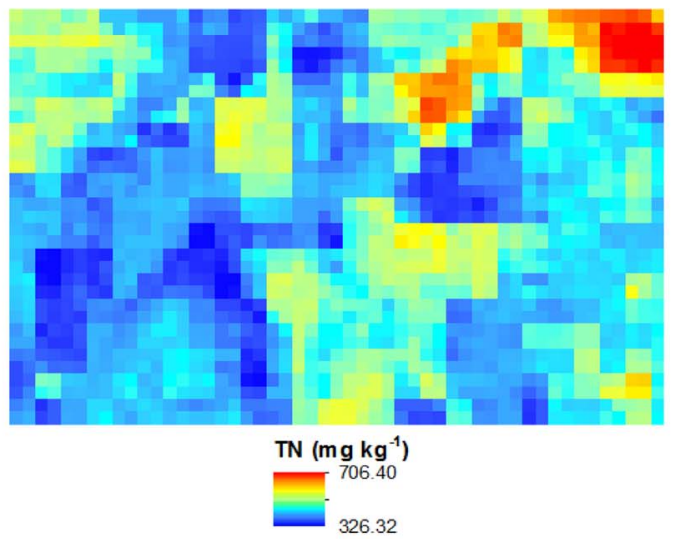

(D)
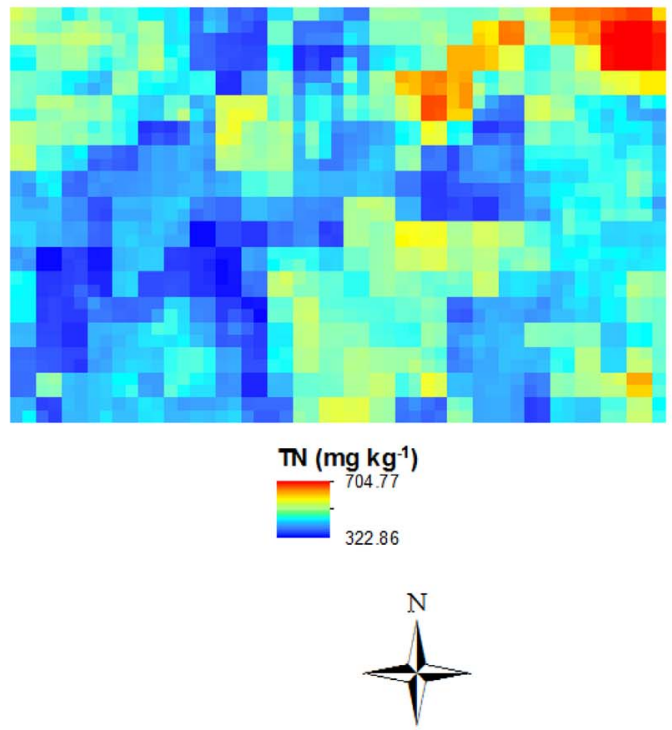

Fig. 7. Soil TN prediction at 0-15 cm depth in Farmland A by (A) Model NLTM, (B) Model NLTB, (C) Model NLTG, (D) Model NLTI.

such as ARVI, CI, and ratio of visible bands from both the PAN and MS images had relatively strong correlations and were identified as relevant variables with TN, confirming the similar spectral characteristics of PAN and MS images. In this research, RG from GS PAN Landsat 8 (LTaGRG) has the strongest correlation with soil TN among all the Landsat 8 spectral indices (Table 4). CI, RB, and RG from three PAN Pleiades-1A images have higher correlations with soil TN compared with all MS WorldView-2/Pleiades-1A spectral indices (Table 6).

\subsection{Comparison of different image pansharpening methods on soil prediction models}

Brovey, IHS, and GS image pan-sharpening methods were classified as a pixel-level image fusion method (Ehlers et al., 2010). It combines the pixel values of different images through some algorithms under strict registration conditions and it has less loss of information compared with feature-level image fusion and decision-level image fusion methods (Hui and Binbin, 2009). Sarp (2014) indicated that GS preserve the spectral and spatial information of original images better than the Brovey and the IHS methods. Ghosh and Joshi (2013) utilized 12 fusion techniques to pansharpen WorldView-2 images, and the quantitative analysis indicated that high-pass filter, PANSHARP, GS and PCA method are the most efficient in increasing spatial resolution, while Brovey and Ehlers methods produced images with significant color distortion. Most research proved the advantages of GS method over IHS and Brovey method in terms of spectral quality preservation, spatial resolution enhancement and color distortion (Jalan and Sokhi, 2012; Yusuf et al., 2013).

In this research, all the soil TN models incorporating the PAN and MS spectral indices had higher spatial resolution and higher model performance than those incorporating MS spectral indices alone. GS images showed higher spatial heterogeneity from visual analysis compared with IHS and Brovey images, and GS/MS-based soil TN models had higher predictive capability than other soil TN models, and GS/MSbased soil TN maps had higher spatial heterogeneity than other soil TN maps. However, no single image pansharpening method is able to improve all the characteristics of the original image (Johnson et al., 2014; Xu et al., 2017). Those PAN/MS image-based soil TN models only show slightly increase of predictive capability compared with MS imagebased models. More research need be performed to evaluate the effects of image pansharpening on soil prediction models in the future.

\subsection{Promotion of remote sensing-based digital soil mapping in smallholder farms}

The very high resolution images especially pansharpened images have strong capability to classify land use/crop types, display the intricate details of the ground features, and help policy makers establish land and soil management policies for smallholder farmers. The spatial pattern of soil $\mathrm{TN}$ is not only affected by soil parental material, 


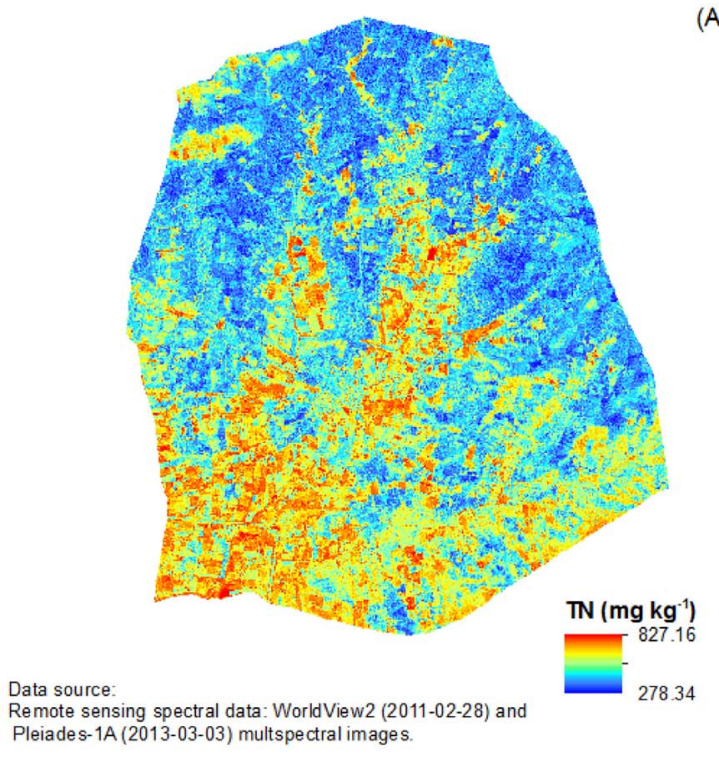

(A) Pleiade s-1A (2013-03-03) multspectral images.

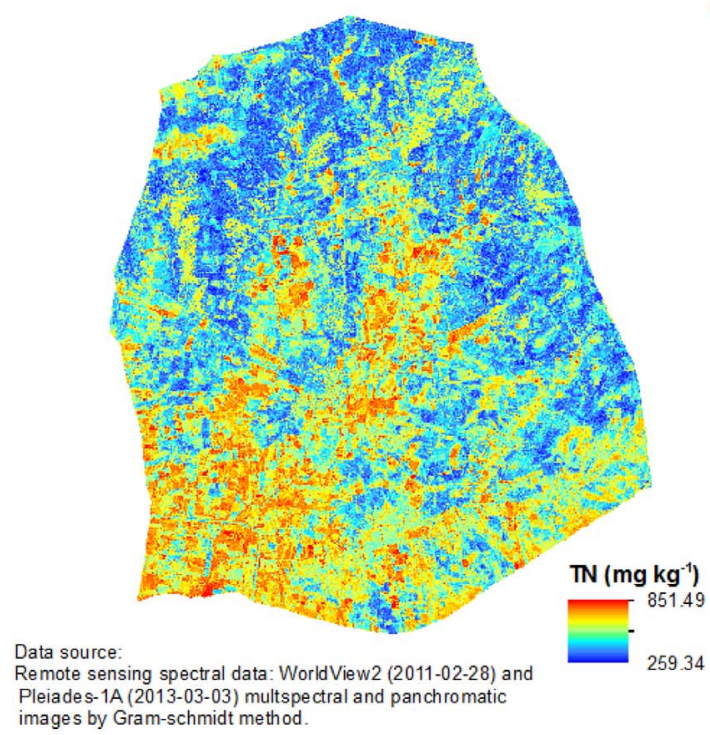

(C)

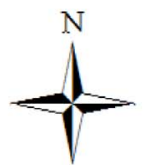

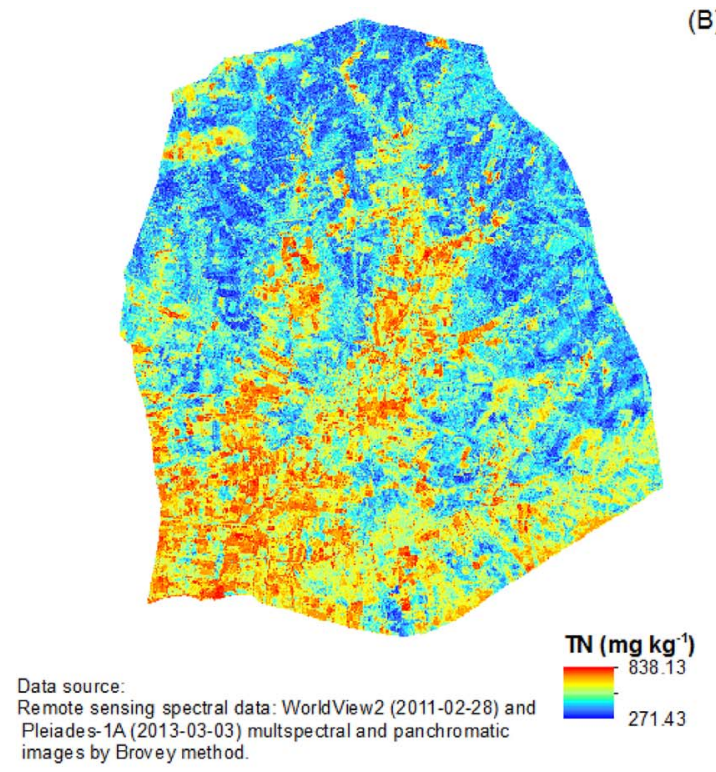

(B)

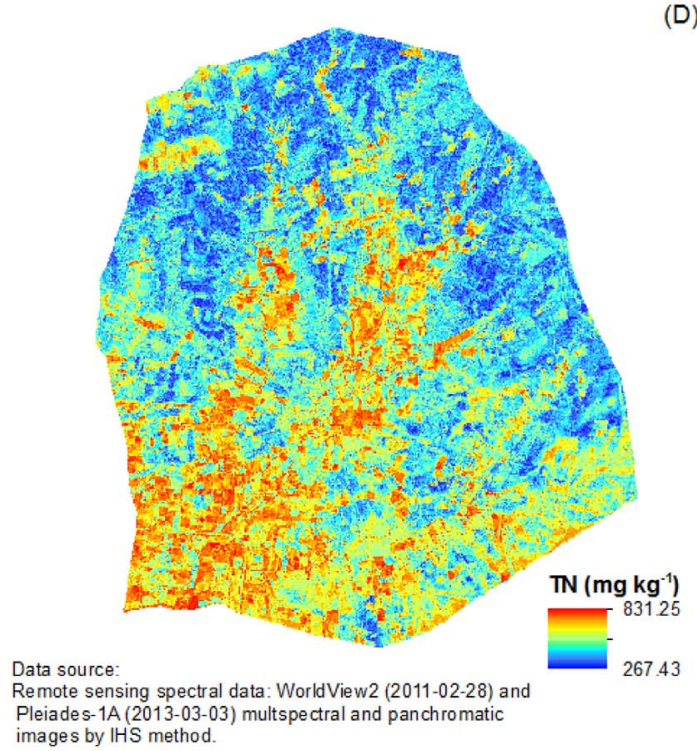

(D)

Fig. 8. Soil TN prediction at 0-15 cm depth in Masuti by (A) Model NWPM, (B) Model NWPB, (C) Model NWPG, (D) Model NWPI.

vegetation, and moisture, which can be indicated by environmental variables (McBratney et al., 2003), but also biogeochemical processes such as volatilization, leaching, surface runoff, nitrification, and denitrification (Bai et al., 2005), and anthropogenic activities such as land use, fertilizer management. Most DSM research utilized environmental variables from various sources such as land use, soil parent material, soil types, temperature, or precipitation (Lamsal and Mishra, 2010; Pahlavan-Rad et al., 2016). Categorical variables such as land use and soil parental material were usually collected from downloadable materials, preliminary investigation, and expert knowledge, which is unavailable in most smallholder village. Those factors pose challenges for accurate prediction of TN in smallholder farm settings. Taking advantage of the data mining methods such as random forest-based Boruta algorithm, the spectral indices from different spectrum region reflecting vegetation, moisture, temperature, and roughness were identified as relevant variables with TN. In this research, remote sensing-based soil TN prediction models attained fair prediction accuracy although there is no categorical variable utilized in soil prediction models.

\subsection{Significance of image pansharpening on digital soil mapping}

Complex fine scale landscape and shortage of environmental variables hindered the technology promotion of DSM research in small farms. This research provides a new paradigm to unlock the potential of the wide application of image pansharpening in DSM domain, as it can enhance the spatial resolution and predictive accuracy of soil prediction models. The utilization of super-fine pansharpened spectral indices from MS and PAN WorldView-2 and Pleiades-1A drives the DSM 
(A)
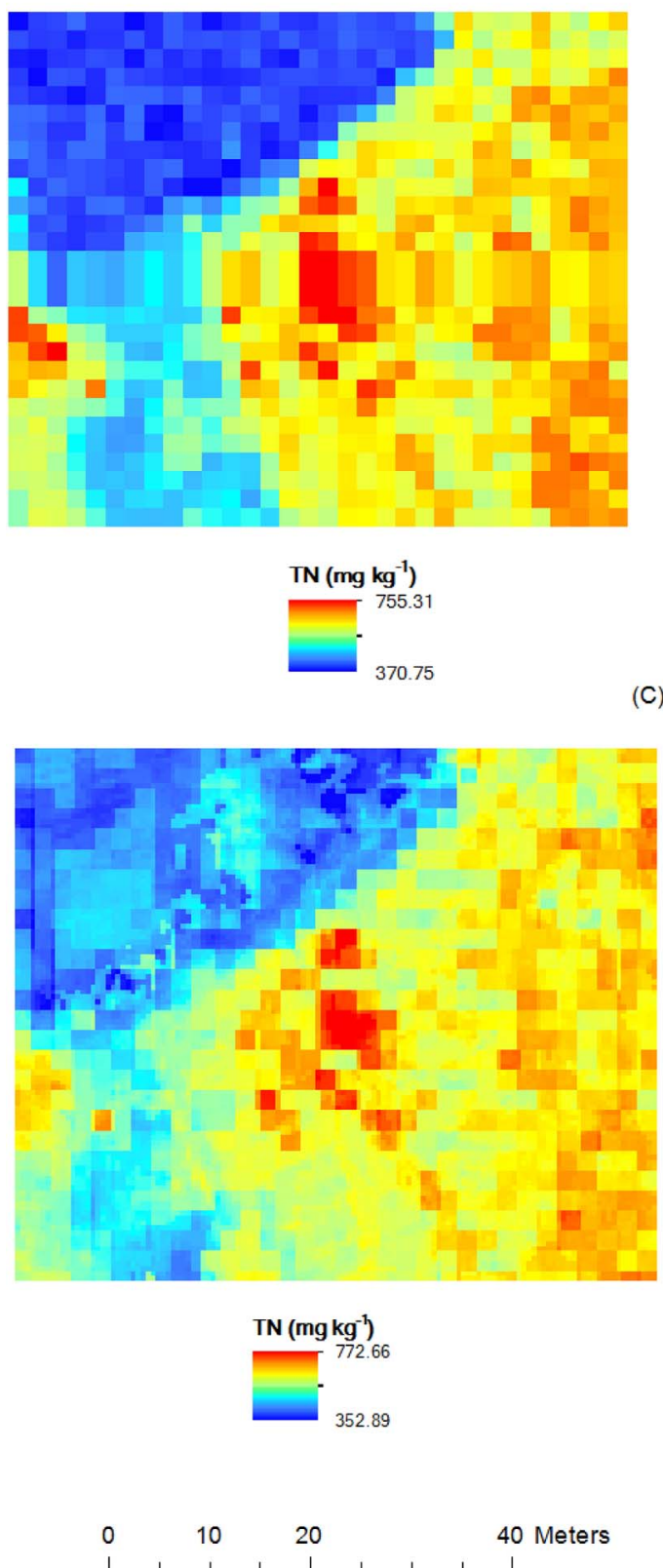

(C)
(B)
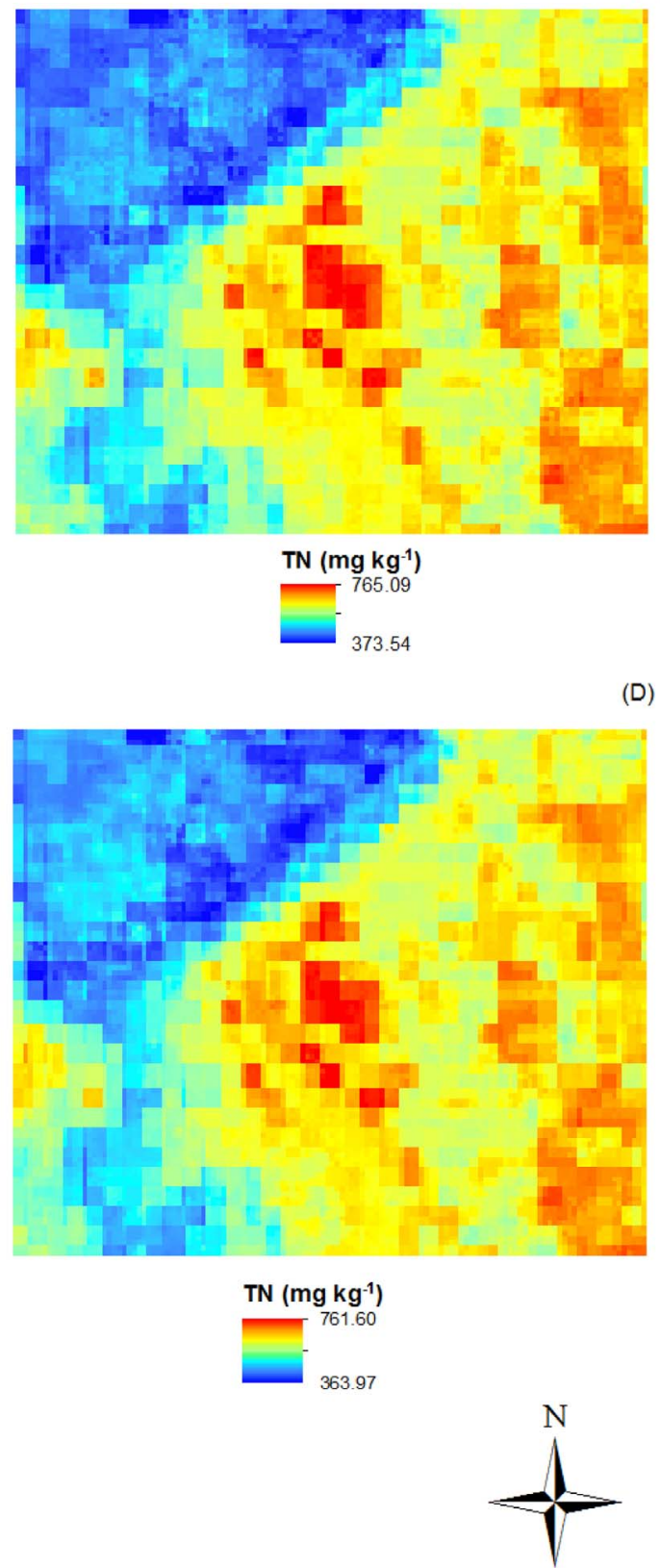

Fig. 9. Soil TN prediction at 0-15 cm depth in Farmland B of Masuti by (A) Model NWPM, (B) Model NWPB, (C) Model NWPG, (D) Model NWPI.

research into a new "exquisite" era that soil maps can characterize the spatial pattern of soil properties at meter/sub-meter scale. However, the research showed the WorldView-2/Pleiades-1A-based soil TN prediction models would not necessarily have stronger prediction capability than the Landsat 8-based soil TN prediction models. Due to the free acquisition of the Landsat 8 images, those Landsat 8 PAN/MS-based soil prediction models have potential to be widely utilized in small farms in developing countries and help them develop more field-specific sustainable soil management schemes.

\section{Conclusions}

Some spectral indices such as ARVI, CI, and ratio of visible bands from both the PAN and MS images had relatively strong correlations and were identified as relevant variables with soil $\mathrm{TN}$, confirming the similar spectral characteristics of PAN and MS spectral indices. The incorporation of PAN spectral indices increased the spatial resolution of the soil prediction models. However, PAN/MS spectral indices-based models only showed slightly higher prediction capability compared with MS spectral-based model. Soil TN models based on Gram-Schmidt PAN and MS spectral indices showed slightly higher prediction capability compared with those based on Intensity-Hue-Saturation and Brovey PAN and MS spectral indices. Overall, the remote sensing-based digital soil mapping have potential to be applied in smallholder farm settings, and image pansharpening techniques have potential to be utilized in digital soil mapping. More research is needed to explore the effects of image pansharpening on soil prediction models in the future.

\section{Acknowledgement}

Funding for this project was provided by the grant award No. 1201943 "Development of a Geospatial Soil-Crop Inference Engine for Smallholder Farmers" EAGER National Science Foundation and Research Foundation for Youth Scholars of Beijing Technology and 
Business University. The soil analysis was performed in the soil laboratory at the International Crops Research Institute for the Semi-Arid Tropics (ICRISAT) in Patancheru/Hyderabad, Telangana State, India. We thank Christopher M. Clingensmith at University of Florida, and other ICRISAT staff members and villagers of Kothapally for support with field sampling. We also thank Yiming Xu's PhD committee members Dr. Thomas K. Frazer and Dr. Vimala D. Nair for their guidance and commitment. A matching assistantship for Yiming Xu was provided by School of Natural Resources and Environment, University of Florida, and China Scholarship Council.

\section{References}

Bai, J., Ouyang, H., Deng, W., Zhu, Y., Zhang, X., Wang, Q., 2005. Spatial distribution characteristics of organic matter and total nitrogen of marsh soils in river marginal wetlands. Geoderma 124, 181-192. http://dx.doi.org/10.1016/j.geoderma.2004.04. 012.

Bannari, A., Morin, D., Bonn, F., Huete, A.R., 1995. A review of vegetation indices. Remote Sens. Rev. 13, 95-120. http://dx.doi.org/10.1080/02757259509532298.

Belnap, J., 2002. Nitrogen fixation in biological soil crusts from southeast Utah, USA. Biol. Fertil. Soils 35, 128-135. http://dx.doi.org/10.1007/s00374-002-0452-x.

Belnap, J., Lange, O.L., 2002. Biological Soil Crusts: Structure, Function, and Management (with 30 Tables). Springer Science \& Business Media.

Beymer, R.J., Klopatek, J.M., 1991. Potential contribution of carbon by microphytic crusts in pinyon-juniper woodlands. Arid Soil Res. Rehabil. 5, 187-198. http://dx. doi.org/10.1080/15324989109381279.

Carper, W.J., 1990. The use of intensity-hue-saturation transformations for merging SPOT panchromatic and multispectral image data. Photogramm. Eng. Remote. Sens. 56, 457-467.

Chavez, P., Sides, S.C., Anderson, J.A., 1991. Comparison of three different methods to merge multiresolution and multispectral data- Landsat TM and SPOT panchromatic. Photogramm. Eng. Remote. Sens. 57, 295-303.

Chen, D., Huang, J., Jackson, T.J., 2005. Vegetation water content estimation for corn and soybeans using spectral indices derived from MODIS near- and short-wave infrared bands. Remote Sens. Environ. 98, 225-236. http://dx.doi.org/10.1016/j.rse. 2005.07.008.

Clevers, J.G.P.W., Gitelson, A.A., 2013. Remote estimation of crop and grass chlorophyll and nitrogen content using red-edge bands on Sentinel-2 and -3. Int. J. Appl. Earth Obs. Geoinf. 23, 344-351. http://dx.doi.org/10.1016/j.jag.2012.10.008.

Cohen, W.B., 1991. Response of vegetation indices to changes in three measures of leaf water stress. Photogramm. Eng. Remote. Sens. 195-202.

Curran, P.J., Catt, J.A., 1994. The relationship between red edge and chlorophyll concentration in the Broadbalk winter wheat experiment at Rothamsted. Int. J. Remote Sens. 15, 705-709. http://dx.doi.org/10.1080/01431169408954110.

Daughtry, C.S.T., Walthall, C.L., Kim, M.S., de Colstoun, E.B., McMurtrey III, J.E., 2000. Estimating corn leaf chlorophyll concentration from leaf and canopy reflectance. Remote Sens. Environ. 74, 229-239. http://dx.doi.org/10.1016/S0034-4257(00) 00113-9.

Delegido, J., Verrelst, J., Meza, C.M., Rivera, J.P., Alonso, L., Moreno, J., 2013. A rededge spectral index for remote sensing estimation of green LAI over agroecosystems. Eur. J. Agron. 46, 42-52. http://dx.doi.org/10.1016/j.eja.2012.12.001.

Dupigny-Giroux, L.-A., Lewis, J.E., 1999. A moisture index for surface characterization over a semiarid area. Photogramm. Eng. Remote. Sens. 65, 937-946.

Ehlers, M., Klonus, S., Johan Åstrand, P., Rosso, P., 2010. Multi-sensor image fusion for pansharpening in remote sensing. Int. J Image Data Fusion 1, 25-45. http://dx.doi. org/10.1080/19479830903561985

Filella, I., Penuelas, J., 1994. The red edge position and shape as indicators of plant chlorophyll content, biomass and hydric status. Int. J. Remote Sens. 15, 1459-1470. http://dx.doi.org/10.1080/01431169408954177.

Gao, B., 1996. NDWI-a normalized difference water index for remote sensing of vegetation liquid water from space. Remote Sens. Environ. 58, 257-266. http://dx.doi. org/10.1016/S0034-4257(96)00067-3.

Ghosh, A., Joshi, P.K., 2013. Assessment of pan-sharpened very high-resolution WorldView-2 images. Int. J. Remote Sens. 34, 8336-8359. http://dx.doi.org/10. 1080/01431161.2013.838706.

Gitelson, A., Merzlyak, M.N., 1994. Spectral reflectance changes associated with autumn senescence of Aesculus hippocastanum L. and Acer platanoides L. leaves. Spectral features and relation to chlorophyll estimation. J. Plant Physiol. 143, 286-292. http:// dx.doi.org/10.1016/S0176-1617(11)81633-0.

Gitelson, A.A., Kaufman, Y.J., Merzlyak, M.N., 1996. Use of a green channel in remote sensing of global vegetation from EOS-MODIS. Remote Sens. Environ. 58, 289-298. http://dx.doi.org/10.1016/S0034-4257(96)00072-7.

Gitelson, A.A., Viña, A., Ciganda, V., Rundquist, D.C., Arkebauer, T.J., 2005. Remote estimation of canopy chlorophyll content in crops. Geophys. Res. Lett. 32, L08403. http://dx.doi.org/10.1029/2005GL022688.

Griffin, M.K., Burke, H.K., 2003. Compensation of hyperspectral data for atmospheric effects. MIT Lincoln Lab. J. 14, 29-54.

Grunwald, S., Thompson, J.A., Boettinger, J.L., 2011. Digital soil mapping and modeling at continental scales: finding solutions for global issues. Soil Sci. Soc. Am. J. 75, 1201. http://dx.doi.org/10.2136/sssaj2011.0025.

Haboudane, D., Miller, J.R., Tremblay, N., Zarco-Tejada, P.J., Dextraze, L., 2002. Integrated narrow-band vegetation indices for prediction of crop chlorophyll content for application to precision agriculture. Remote Sens. Environ. 81, 416-426. http:// dx.doi.org/10.1016/S0034-4257(02)00018-4.

Hervieu, A., Le Bris, A., Mallet, C., 2016. Fusion of hyperspectral and Vhr multispectral image classifications in urban areas. ISPRS Ann. Photogramm. Remote Sens. Spat. Inf. Sci. 457-464.

Hitziger, M., Ließ, Mareike, 2014. Comparison of three supervised learning methods for digital soil mapping: application to a complex terrain in the Ecuadorian Andes. Appl. Environ. Soil Sci. 2014, e809495. http://dx.doi.org/10.1155/2014/809495.

Holzman, M.E., Rivas, R., Piccolo, M.C., 2014. Estimating soil moisture and the relationship with crop yield using surface temperature and vegetation index. Int. J. Appl. Earth Obs. Geoinf. 28, 181-192. http://dx.doi.org/10.1016/j.jag.2013.12.006.

Hui, T., Binbin, W., 2009. Discussion and Analyze on Image Fusion Technology. Presented at the Machine Vision, 2009. ICMV'09. Second International Conference on, IEEE. pp. 246-250.

Jalan, S., Sokhi, B.S., 2012. Comparison of different pan-sharpening methods for spectral characteristic preservation: multi-temporal CARTOSAT-1 and IRS-P6 LISS-IV imagery. Int. J. Remote Sens. 33, 5629-5643. http://dx.doi.org/10.1080/01431161. 2012.666811.

Jawak, S.D., Luis, A.J., 2013. Improved land cover mapping using high resolution multiangle 8-band WorldView-2 satellite remote sensing data. J. Appl. Remote. Sens. 7 , 073573.

Johnson, B.A., Scheyvens, H., Shivakoti, B.R., 2014. An ensemble pansharpening approach for finer-scale mapping of sugarcane with Landsat 8 imagery. Int. J. Appl. Earth Obs. Geoinf. 33, 218-225. http://dx.doi.org/10.1016/j.jag.2014.06.003.

Jones, H.G., Serraj, R., Loveys, B.R., Xiong, L., Wheaton, A., Price, A.H., 2009. Thermal infrared imaging of crop canopies for the remote diagnosis and quantification of plant responses to water stress in the field. Funct. Plant Biol. 36, 978-989.

Karnieli, A., 1997. Development and implementation of spectral crust index over dune sands. Int. J. Remote Sens. 18, 1207-1220. http://dx.doi.org/10.1080/ 014311697218368

Kaufman, Y.J., Tanré, D., 1996. Strategy for direct and indirect methods for correcting the aerosol effect on remote sensing: from AVHRR to EOS-MODIS. Remote Sens. Environ. 55, 65-79. http://dx.doi.org/10.1016/0034-4257(95)00193-X.

Kelly (Letcher), R.A., Jakeman, A.J., Barreteau, O., Borsuk, M.E., ElSawah, S., Hamilton, S.H., Henriksen, H.J., Kuikka, S., Maier, H.R., Rizzoli, A.E., van Delden, H., Voinov, A.A., 2013. Selecting among five common modelling approaches for integrated environmental assessment and management. Environ. Model. Softw. 47, 159-181. http://dx.doi.org/10.1016/j.envsoft.2013.05.005.

Krom, M.D., 1980. Spectrophotometric determination of ammonia: a study of a modified Berthelot reaction using salicylate and dichloroisocyanurate. Analyst 105, 305-316. http://dx.doi.org/10.1039/AN9800500305.

Laben, C.A., Brower, B.V., 2000. Process for Enhancing the Spatial Resolution of Multispectral Imagery Using Pan-Sharpening. (US6011875 A).

Lamsal, S., Mishra, U., 2010. Mapping soil textural fractions across a large watershed in north-east Florida. J. Environ. Manag. 91, 1686-1694. http://dx.doi.org/10.1016/j. jenvman.2010.03.015.

Li, F., Miao, Y., Feng, G., Yuan, F., Yue, S., Gao, X., Liu, Y., Liu, B., Ustin, S.L., Chen, X., 2014. Improving estimation of summer maize nitrogen status with red edge-based spectral vegetation indices. Field Crop Res. 157, 111-123. http://dx.doi.org/10. 1016/j.fcr.2013.12.018.

Lobell, D.B., Burke, M.B., Tebaldi, C., Mastrandrea, M.D., Falcon, W.P., Naylor, R.L., 2008. Prioritizing climate change adaptation needs for food security in 2030 . Science 319, 607-610. http://dx.doi.org/10.1126/science.1152339.

Lottering, R., Mutanga, O., 2016. Optimising the spatial resolution of WorldView-2 pansharpened imagery for predicting levels of Gonipterus scutellatus defoliation in KwaZulu-Natal, South Africa. ISPRS J. Photogramm. Remote Sens. 112, 13-22. http://dx.doi.org/10.1016/j.isprsjprs.2015.11.010.

McBratney, A.B., Mendonça Santos, M.L., Minasny, B., 2003. On digital soil mapping. Geoderma 117, 3-52. http://dx.doi.org/10.1016/S0016-7061(03)00223-4.

McKenna Neuman, C., Maxwell, C.D., Boulton, J.W., 1996. Wind transport of sand surfaces crusted with photoautotrophic microorganisms. Catena 27, 229-247. http://dx doi.org/10.1016/0341-8162(96)00023-9.

Musick, H.B., Pelletier, R.E., 1988. Response to soil moisture of spectral indexes derived from bidirectional reflectance in thematic mapper wavebands. Remote Sens. Environ. 25, 167-184. http://dx.doi.org/10.1016/0034-4257(88)90099-5.

Nellis, M.D., Briggs, J.M., 1992. Transformed vegetation index for measuring spatial variation in drought impacted biomass on Konza Prairie, Kansas. Trans. Kans. Acad. Sci. 1903-95, 93-99. http://dx.doi.org/10.2307/3628024.

Pahlavan-Rad, M.R., Khormali, F., Toomanian, N., Brungard, C.W., Kiani, F., Komaki, C.B., Bogaert, P., 2016. Legacy soil maps as a covariate in digital soil mapping: a case study from northern Iran. Geoderma 279, 141-148. http://dx.doi.org/10.1016/j. geoderma.2016.05.014.

Pathak, H., 2010. Trend of fertility status of Indian soils. Curr. Adv. Agric. Sci. 2, 10-12.

Qi, J., Chehbouni, A., Huete, A.R., Kerr, Y.H., Sorooshian, S., 1994. A modified soil adjusted vegetation index. Remote Sens. Environ. 48, 119-126. http://dx.doi.org/10. 1016/0034-4257(94)90134-1.

Rikimaru, A., Miyatake, S., 1997. Development of Forest Canopy Density Mapping and Monitoring Model Using Indices of Vegetation, Bare Soil and Shadow. (Available Http Www Gisdevelopment Netaarsacrs1997ts5index Shtmm).

Rock, B.N., Vogelmann, J.E., Williams, D.L., Vogelmann, A.F., Hoshizaki, T., 1986. Remote detection of forest damage. Bioscience 36, 439-445. http://dx.doi.org/10 $2307 / 1310339$.

Rogers, A.S., Kearney, M.S., 2004. Reducing signature variability in unmixing coastal marsh Thematic Mapper scenes using spectral indices. Int. J. Remote Sens. 25, 2317-2335. http://dx.doi.org/10.1080/01431160310001618103.

Rouse, J.W., Haas, R.H., Schell, J.A., Deering, D.W., 1974. Monitoring vegetation systems 
in the great plains with Erts. NASA Spec. Publ. 351, 309.

Roy, D.P., Wulder, M.A., Loveland, T.R., C.E, W., Allen, R.G., Anderson, M.C., Helder, D., Irons, J.R., Johnson, D.M., Kennedy, R., Scambos, T.A., Schaaf, C.B., Schott, J.R., Sheng, Y., Vermote, E.F., Belward, A.S., Bindschadler, R., Cohen, W.B., Gao, F., Hipple, J.D., Hostert, P., Huntington, J., Justice, C.O., Kilic, A., Kovalskyy, V., Lee, Z.P., Lymburner, L., Masek, J.G., McCorkel, J., Shuai, Y., Trezza, R., Vogelmann, J., Wynne, R.H., Zhu, Z., 2014. Landsat-8: science and product vision for terrestrial global change research. Remote Sens. Environ. 145, 154-172. http://dx.doi.org/10 1016/j.rse.2014.02.001.

Rudnicki, W., Kursa, M., 2010. Feature selection with the boruta package. J. Stat. Softw. $36,1-13$.

Sanchez, P.A., Ahamed, S., Carré, F., Hartemink, A.E., Hempel, J., Huising, J., Lagacherie, P., McBratney, A.B., McKenzie, N.J., Mendonça-Santos, M., de L., Minasny, B., Montanarella, L., Okoth, P., Palm, C.A., Sachs, J.D., Shepherd, K.D., Vågen, T.-G., Vanlauwe, B., Walsh, M.G., Winowiecki, L.A., Zhang, G.-L., 2009. Digital soil map of the world. Science 325, 680-681. http://dx.doi.org/10.1126/science.1175084.

Sarp, G., 2014. Spectral and spatial quality analysis of pan-sharpening algorithms: a case study in Istanbul. Eur. J. Remote Sens. 47, 19-28.

Schlund, M., von Poncet, F., Hoekman, D.H., Kuntz, S., Schmullius, C., 2014. Importance of bistatic SAR features from TanDEM-X for forest mapping and monitoring. Remote Sens. Environ. 151, 16-26. (Special Issue on 2012 ForestSAT). https://doi.org/10. 1016/j.rse.2013.08.024.

Sims, D.A., Gamon, J.A., 2002. Relationships between leaf pigment content and spectral reflectance across a wide range of species, leaf structures and developmental stages.
Remote Sens. Environ. 81, 337-354. http://dx.doi.org/10.1016/S0034-4257(02) 00010-X.

Vrabel, J., 2000. Multispectral imagery advanced band sharpening study. Photogramm. Eng. Remote. Sens. 66, 73-80.

Wani, S.P., 2012. Bhoochetana: Mission to Boost Productivity of Rainfed Agriculture through Science-led Interventions in Karnataka. International Crops Research Institute for Semi-Arid Tropics, Patancheru, Andhra Pradesh India.

Williams, P., 2001. Near-Infrared Technology: In the Agricultural and Food Industries, 2 edition. Amer Assn of Cereal Chemists, St. Paul, Minn.

Williams, P., Norris, K., 1987. Near-infrared technology in the agricultural and food industries. American Association of Cereal Chemists Inc.

Wolf, A., 2010. Using WorldView 2 Vis-NIR MSI Imagery to Support Land Mapping and Feature Extraction Using Normalized Difference Index Ratios (Presented at the Proc). SPIE.

Xu, Y., Smith, S.E., Grunwald, S., Abd-Elrahman, A., Wani, S.P., 2017. Incorporation of satellite remote sensing pan-sharpened imagery into digital soil prediction and mapping models to characterize soil property variability in small agricultural fields. ISPRS J. Photogramm. Remote Sens. 123, 1-19. http://dx.doi.org/10.1016/j. isprsjprs.2016.11.001.

Yusuf, Y., Sri Sumantyo, J.T., Kuze, H., 2013. Spectral information analysis of image fusion data for remote sensing applications. Geocarto Int. 28, 291-310. http://dx.doi. org/10.1080/10106049.2012.692396.

Zhang, J., 2010. Multi-source remote sensing data fusion: status and trends. Int. J. Image Data Fusion 1, 5-24. http://dx.doi.org/10.1080/19479830903561035. 